\title{
Predictive language comprehension in Parkinson's disease
}

Katharine Aveni ${ }^{\mathrm{a}}$, Juweiriya Ahmed ${ }^{\mathrm{b}, 1}$, Arielle Borovsky ${ }^{\mathrm{c}}$, Ken McRae ${ }^{\mathrm{b}}$, Mary E.

Jenkins $^{\mathrm{d}}$, Katherine Sprengel ${ }^{\mathrm{a}}$, J. Alexander Fraser ${ }^{\mathrm{d}, \mathrm{e}}$, Joseph B. Orange ${ }^{\mathrm{f}, \mathrm{g}}$, Thea

Knowles $^{\mathrm{b}, 2}$, and Angela C. Roberts ${ }^{\mathrm{a}^{*}}$

${ }^{a}$ Roxelyn and Richard Pepper Department of Communication Sciences and Disorders,

Northwestern University, Evanston IL, United States

${ }^{\mathrm{b}}$ Department of Psychology, Western University, London ON, Canada

${ }^{\mathrm{c}}$ Department of Speech, Language, and Hearing Sciences, Purdue University, West Lafayette IN, United States

${ }^{\mathrm{d}}$ Department of Clinical Neurological Sciences, Schulich School of Medicine and Dentistry, Western University, London ON, Canada

e Department of Ophthalmology, Western University, St. Joseph's Health Care, London ON,

Canada

${ }^{\mathrm{f}}$ School of Communication Sciences and Disorders, Western University, London ON, Canada

${ }^{\mathrm{g}}$ Canadian Centre for Activity and Aging, Western University, London ON, Canada

${ }^{*}$ Roxelyn and Richard Pepper Department of Communication Sciences and Disorders, Northwestern University, 2240 Campus Drive Evanston IL, United States 60208 angela.roberts@ northwestern.edu

\footnotetext{
${ }^{1}$ Present address Temerty Faculty of Medicine, University of Toronto, Toronto ON, Canada

${ }^{2}$ Present address Department of Communicative Disorders \& Sciences, University at Buffalo, Buffalo, NY, United States
} 


\section{Predictive language comprehension in Parkinson's disease}

Language impairment in Parkinson's disease (PD) may be attributable to motor and action/event knowledge deficits. We predicted that cognitively intact PD participants would be impaired in anticipating objects in sentences from event-based thematic fit information. Twenty-four PD and 24 healthy age-matched participants completed comprehensive neuropsychological assessments. We recorded participants' eye movements as they heard predictive (The fisherman rocks the boat) and non-predictive baseline sentences (Look at the bathtub). Predictive sentences contained target, agent-related, verb-related, and unrelated images. Baseline sentences used phonologically and semantically unrelated distractors. We tested effects of group (PD/control) on gaze using growth curve models. There were no significant differences between PD and control participants in either sentence type, suggesting that PD participants successfully and rapidly use combinatory thematic fit information to predict upcoming language. Additionally, we conducted an exploratory analysis contrasting PD and controls' performance on low motion content versus high motion content verbs. This analysis revealed fewer predictive fixations in high-motion sentences only for healthy older adults, suggesting that people with Parkinson's disease may adapt to their disease by relying on spared, non-action-simulation-based language prediction and processing mechanisms. Given that multiple studies have shown that individuals with PD have difficulty processing verbs, it is highly surprising that they match healthy adults in their ability to use verb meaning to predict upcoming nouns.

Keywords: Parkinson disease; visual world paradigm; language prediction; action semantics; eye tracking 


\section{Introduction}

\section{Background}

Among adults aged 65 and older, Parkinson's disease (PD) is the second most common neurodegenerative disorder globally (Hirtz et al., 2007; Pringsheim et al., 2014). Characterized by a resting-state tremor, rigidity, bradykinesia, and/or postural instability, PD is often accompanied by secondary motor and non-motor features including cognitive decline and, less commonly, outright dementia (Hely et al., 2005; Jankovic, 2008). These impairments result, in large part, from the progressive loss of dopaminergic neurons in substantia nigra pars compacta (Dauer \& Przedborski, 2003) and by the disruption of neural connections among basal ganglia structures and diverse cortical regions (Alexander et al., 1986; Middleton \& Strick, 2000; Wu et al., 2012). Language impairments in PD include impaired processing of action words and concepts (e.g., Cardona et al., 2013; Cousins et al., 2018; Gallese \& Cuccio, 2018; Roberts et al., 2017), impaired comprehension of complex syntactic structures (e.g., Grossman, 1999), impaired spoken language production marked by reduced information content (specifically less

complete/accurate event structures), increased frequency of grammatical errors (Ash et al., 2017; Godbout \& Doyon, 2000; Murray, 2000; Roberts \& Post, 2018), and difficulties interpreting figurative language and semantic ambiguities (Berg et al., 2003; Humphries et al., 2019; Lewis et al., 2007). Because language prediction in healthy adults relies in part on complex combinatorial and event simulation mechanisms (Huettig, 2015), language prediction is plausibly altered in people with Parkinson's and related diseases. However, it remains unclear whether PD impairs language prediction based on agent- and verb-specific semantic knowledge.

Verb processing impairments in PD

Verb processing deficits are widely reported in Parkinson's disease and have been demonstrated across a variety of comprehension and production tasks. People with PD have been 
shown to perform worse than control participants in semantic-based verbal fluency and action fluency tasks (Auclair-Ouellet et al., 2020; Auriacombe et al., 1993), even in the absence of cognitive impairment (Péran et al., 2003; Piatt et al., 1999). People with PD show selective deficits in action word processing (Bocanegra et al., 2017; Bocanegra et al., 2015; Boulenger et al., 2008; Cardona et al., 2013; Fernandino et al., 2013; Roberts et al., 2017) including in verb production and naturalistic discourse tasks (Cotelli et al., 2007; Cousins et al., 2018; Crescentini et al., 2008; Garcia et al., 2018; Garcia et al., 2016; Herrera et al., 2012). Several possible accounts of verb processing deficits in PD have been provided.

It has been argued that executive function/attention impairments explain language deficits in PD (Dubois \& Pillon, 1997; Kudlicka et al., 2011; Mega \& Cummings, 2001; Zgalijardic et al., 2003). Colman et al. (2009) found that PD participants were impaired at producing verbs within a sentence context and that the degree of impairment significantly correlated with performance on set switching and working memory tasks. Additionally, altered lexical-semantic priming in PD (Copland, 2003; Copland et al., 2000a, 2000b; Copland et al., 2001) has been attributed to potential disruption of the anterior cingulate loop (Copland, 2003) and associated disruptions in executive function (Posner \& Digirolamo, 1998). For example, Copland (2003) presented polysemous words (e.g., bank (money)-bank (river)) to participants and found that multiple word meanings were primed for a significantly extended period of time in PD participants compared to controls, suggesting that altered attention-mediated processing may drive lexical-semantic impairments. Similarly, PD participants show poor comprehension of syntactically complex sentences (Geyer \& Grossman, 1994; Grossman et al., 1992; Lieberman et al., 1992), perhaps because attention/executive control is needed to process sentences that have 
complex mappings between thematic (semantic) roles and syntactic structures (Grossman, 1999; McCarthy \& Warrington, 1987).

Alternatively, proponents of embodied cognition suggest that semantic memory is distributed across, and grounded in, modality-specific sensory, motor, and emotion systems (Binder \& Desai, 2011; Pulvermüller, 2018a). Embodied cognition theories predict that the motor impairments characteristic of PD should impair action concept and verb processing even in the absence of cognitive impairment (Bak, 2013). In this vein, Cardona et al. (2013) reviewed studies of action-verb, semantic, and morphosyntactic processing in PD. Cardona et al. proposed that action-language networks involve not only motor cortex and respective mirror neuron systems but also cortical-subcortical systems. Action and body motion verbs have been shown to be more affected by PD than non-action verbs (Bocanegra et al., 2017; Cousins et al., 2018; Herrera et al., 2012). Additionally, people with PD without mild cognitive impairment have shown poorer comprehension of high action content discourse passages than low action content passages (Garcia et al., 2018). Studies that examined participants' executive function abilities showed that they did not explain these action-language deficits (Bocanegra et al., 2015; Garcia et al., 2017). Furthermore, Roberts et al. (2017) showed that the degree of action word processing impairment relates to the degree of motor impairment in the action-associated limbs.

Deficits in representation and knowledge of real-world events may also explain verb processing impairments in PD. Godbout and Doyon (2000) asked people with PD to produce scripts describing sequences of complex activities. They found more sequencing and intrusion errors in PD than in controls, leading the authors to suggest that changes in frontostriatal loops in PD may affect event representations. This finding is consistent with Roberts and Post (2018), who found that individuals with PD generated fewer event casts (main story units grounded in an 
action event) than controls when producing spontaneous narratives. If event knowledge deficits are a symptom of Parkinson's disease, then cognitively intact participants with Parkinson's disease may show impaired processing of verbs and of their event-based semantic associates, compared to healthy adults. Online language processing may be particularly challenging for people with PD, considering that healthy adults activate event knowledge both to process and to predict language as it unfolds in real time.

\section{Language prediction in healthy adults}

In healthy adults, on-line sentence comprehension rapidly uses verb-specific syntactic and semantic information to predict upcoming words and structures (Garnsey et al., 1997; Trueswell et al., 1993). Healthy adults are slower to read information that violates selectional restrictions, such as a requirement for a verb's object to be animate (Altmann, 1999; Altmann \& Mirković, 2009). Similarly, when listening to sentences, adults saccade to a target object more quickly when the verb's selectional restrictions uniquely identify a target object than when the verb is nonselective (Altmann \& Kamide, 1999). Furthermore, healthy adults may predict upcoming language not only from syntactic constraints (Bornkessel \& Schlesewsky, 2006; Rayner et al., 2004; Warren \& McConnell, 2007) but also from event-based thematic fit information-the plausibility that a given noun phrase serves as the agent (or patient, goal, etc.) of a verbal predicate (Altmann \& Mirković, 2009; DeLong et al., 2005; Kuperberg \& Jaeger, 2016). For example, in healthy young adults, cop is considered a typical agent of arrested but not a typical patient of arrested; longer reading times were found for sentences that violated this thematic fit expectation (e.g., The cop arrested by the detective was guilty of taking bribes; McRae et al., 1998). As further evidence of semantic-based language prediction, in several ERP experiments, it has been shown that semantically constrained sentences produce a semantic prediction potential in cortical locations that reflect the semantic features of the anticipated stimuli (Grisoni 
et al., 2017; Grisoni et al., 2021; Leon-Cabrera et al., 2019; Pulvermüller \& Grisoni, 2020). Importantly, healthy adults may go beyond word-pair associations and anticipate upcoming material by combining event-based knowledge activated by an agent noun with the event-based knowledge of either a noun or a verb (Hare et al., 2009; Kamide et al., 2003; McRae et al., 2005). This anticipatory effect has been demonstrated even when possible targets are not constrained by visual context (Bicknell et al., 2010). Thus, healthy adults spontaneously predict upcoming semantics and syntactic structures even in situations in which prediction is contingent on multiple sources of probabilistic semantic information.

Interestingly, Pickering and Garrod (2013) suggest that healthy adults are able to predict others' language production because production and comprehension skills are intertwined. Inspired by motor control theories, Pickering and Garrod suggest that speakers create forward models - essentially, internal predictions of their own articulations — allowing speakers to compare their predicted utterances to their actual utterances as they unfold. Listeners may then use a perceived utterance to infer the production command and then use that (inferred) production command to simulate the speaker's language output. In support of this theory, Pickering and Garrod note that: 1) interlocutors' speech production on a shared topic often overlaps during conversational discourse, 2) language comprehension may interfere with language production (Schriefers et al., 1990), and 3) there appear to be shared neural pathways supporting language production and comprehension (Scott \& Johnsrude, 2003; Wilson et al., 2004). Importantly, under this theory, because healthy adults predict upcoming language not only using semantic relations but also by (motor speech) simulation, language production impairments may also impair language comprehension and prediction-by-simulation. Thus, 
given the complexity of PD symptoms across motor and cognitive domains, even subtle impairments may significantly disrupt everyday language processing in PD.

\section{Language prediction in $P D$}

Interestingly, people with PD have exhibited deficits in non-linguistic prediction tasks that require using probabilistic, implicitly learned information (Moody et al., 2004; Siegert et al., 2006). In a study of sensory decision-making, people with PD failed to appropriately adjust their response biases in situations where participants should have implicitly learned that one outcome was more common (Perugini et al., 2016). Implicitly learned thematic fit information may be affected similarly in PD. While there is no broad consensus on the nature of the mechanism(s) supporting language prediction, (Huettig, 2015) suggests that a minimum of four predictive mechanisms are needed to fully account for language prediction abilities in healthy adults - a production-based mechanism, a simple associative mechanism, a combinatorial mechanism, and an event simulation-based mechanism. Under Huettig's account, deficits in the use of verbspecific thematic fit information in PD would appear capable of disrupting the proper functioning of multiple language prediction mechanisms.

Previously published studies of verb processing in PD primarily have assessed priming effects and offline language processing rather than on-line sentence comprehension that is more akin to everyday language use. Additionally, prior studies of verb and action processing in PD that relied on brief cognition screening tools may have unknowingly included some participants with cognitive impairment. Relatively few published studies have investigated predictive processing based on thematic fit in cognitively intact participants with PD. Moreover, the experimental methods used in these existing studies are not particularly sensitive to subtle differences in predictive processing. In a self-paced reading task in which participants were asked to indicate if and when a sentence "stopped making sense," Whiting et al. (2005) found 
that people with PD were less sensitive to violations of verb selectional restrictions than controls. This study demonstrated on-line differences in sentence processing in PD but was implemented in a self-paced reading study and relied on relatively coarse-grained manipulations of thematic roles such as animacy violations. Santerre (2015) recorded eye movements using a visual world paradigm to compare healthy older adult and PD participants' abilities to predict target objects based on selective verbs (e.g., eat) versus nonselective verbs (e.g., see). Surprisingly, despite previous findings showing that PD participants experience difficulty accessing action concepts, PD participants showed a similar proportion of fixations on the target objects as did controls in the selective verb trials. The groups' similarity in anticipatory gaze patterns suggests that people with PD show intact on-line processing in relatively simple predictive contexts, in which participants are required to activate and use the meaning of only a single verb. Thus, what remains unclear is whether language prediction deficits appear in PD in situations that require rapid integration of concepts for combinatorial processing, as in combining agent-based and verb-based sources of semantic information.

\section{Present Study}

\section{Objectives and hypothesis}

Our objective was to test, using highly sensitive experimental methods and in a wellcharacterized group of participants, whether Parkinson's disease impairs online language prediction based on combinatorial thematic fit information (e.g., using the combination of fisherman and rocks to predict the target object boat; or using the combination of grandmother and rocks to predict the target object cradle.) We hypothesized that because people with PD evince impairments in action and event semantic knowledge, they should show impaired online processing of sentences that require rapidly combining thematic fit information from an agent noun and a verb to predict the post-verb object (patient). In addition, because recent studies 
suggest that PD particularly affects the semantic representations of action verbs, we further predicted that participants with PD would be more impaired at processing action verbs (rated as having high motion content) than non-action verbs (rated as having low motion content). Although attention, working memory, and executive function impairments have sometimes been implicated in language processing impairments in $\mathrm{PD}$, the objective of the present study was to investigate combinatorial semantic language prediction abilities in a cohort without concomitant cognitive impairment.

\section{Approach}

We used a visual world eye-tracking protocol to examine predictive language comprehension in participants with PD. Participants heard syntactically simple sentences while their eye movements to onscreen images were recorded. The timing and proportions of fixations on target versus distractor objects revealed how quickly the listener integrated relevant pieces of semantic information. The visual world paradigm provides several advantages compared to tasks involving manual responses and/or self-paced reading. First, eye-tracking does not require a manual limb response, which can be slowed in people with PD compared to healthy controls. Secondly, measuring eye movements towards images while sentences are spoken allows us to assess processing before an expected word is spoken, rather than measuring changes in processing that occur after the presentation of the word, as in reading protocols (Huettig, 2015). Finally, the structure of distractor images allows us to infer how multiple cues influenced participants' evolving predictions across a sentence.

Aim 1 examined whether the inability to integrate multiple sources of thematic role information, grounded in deficits in event knowledge, is a source of language impairment in PD. Participants completed a visual world paradigm study in which sentences were uniquely predictable only from the combination of the agent and verb (predictive sentences: e.g. The 
fisherman $_{\text {-agent }}$ rocks-verb the boat-patient). Each trial included an image of the target (e.g., boat) and three distractor images. One distractor was an image of an object semantically related to the agent, but not to the verb (e.g., net), while another was related to the verb only (e.g., cradle). The third distractor was unrelated to the agent, verb, and target object (e.g, quilt). These sentences were designed to be canonical and syntactically simple so that they would not place high demands on participants' cognitive abilities. When typical listeners hear the agent noun, we expect them to fixate the target and agent-related images (with fewer fixations on the verbrelated and unrelated images). Shortly after the onset of the verb, typical listeners are expected to fixate predominantly on the target object. If people with PD have difficulty integrating probabilistic semantic information from agents and verbs to predict an associated patient noun, then we predict that PD participants should show reduced proportions of anticipatory fixations or reduced rate of increase in proportions of anticipatory fixations on target (patient) objects.

Aim 2 assessed whether group differences in on-line sentence processing result merely from impaired object recognition or altered saccadic eye movements rather than from impaired combinatorial semantic processes. If on-line sentence processing impairments in PD are specifically caused by combinatorial semantic impairments, then we predict that adults with PD should not differ from healthy adults in simple sentences where the target objects are explicit, as found in previous work (Santerre, 2015). To address Aim 2, we presented participants with sentences in which the final word was not semantically associated with the verb or other words in the sentence ("baseline sentences," e.g. Look at the $\underline{\text { bathtub }}$ ). Scenes contained a target image (e.g. bathtub) and three semantically and phonologically unrelated items (e.g. violin, slide, dress). These baseline sentences differed in structure from the experimental, predictive sentences because they were not designed to be compared directly with the experimental sentences. 
Instead, because few previously published studies used eye tracking methodology with participants with PD, these sentences served as a control condition designed to ensure that PD participants showed intact lexical recognition and intact saccadic eye movements.

\section{Method}

All study procedures were approved by the Institutional Review Board at Northwestern University. Participants provided written consent for study participation and were compensated for their study participation. All data were collected and analyzed at Northwestern University in the senior author's research lab. Deidentified data (raw and processed) and experiment delivery code are archived with the Northwestern University Library system and will be provided by the corresponding author upon request. Norming data for all experimental stimuli are publicly available using the link provided in the Data availability statement.

\section{Norming studies for stimuli used in the predictive visual world paradigm task}

Ideal target items were expected to possess high event-based associations with both the agent and the verb in the stimulus sentences. Just as importantly, distractor items were required to be minimally associated with the agent and verb. Norming Study 1, which largely used stimuli from a child language study (Borovsky et al., 2012), revealed at least one problematic component in each of the original proposed stimuli sets for our older adult cohort. These problematic items necessitated the creation and norming of additional test items in order to generate the number of items required for the visual world paradigm experiment.

\section{Participants}

Healthy older participants were recruited from research registries and community sources (e.g., flyers, support group outreach programs) using a convenience sampling approach. Eligible participants between the ages of 50 and 90 were required to: have at minimum a grade 10 education; have a minimum grade 10 reading ability based on the Quick Adult Reading 
Inventory (QARI; Chall et al., 2003); and to speak English as their primary language (brief version of the Language Experience and Proficiency-Questionnaire score $\geq 7$ speaking and understanding; Marian et al., 2007). Participants were excluded if they were unwilling to complete the survey in electronic format, had any past medical history of neurosurgical procedures, or had a medical history of major psychiatric or neurological illness. Participants with dementia were excluded with either the in-person (norming study 1) or telephone version (norming study 2) of the Montreal Cognitive Assessment (MoCA) using the respective dementia cut-off scores for each version (Landsheer, 2020; Nasreddine, 2016; Nasreddine et al., 2005; Pugh et al., 2018).

Individuals who participated in Norming Study 1 were also invited to participate in Norming Study 2 because there was no overlap in items between the first and second norming studies and because the studies were conducted $\sim 8$ months apart. In norming study 2 , participants were allowed to complete the study from their home computer to reduce participation burden. To align the normative sample with the anticipated ages in our PD cohort, we intentionally and equitably sampled from younger-old and older-old cohorts. Full participant demographics for individuals participating in the norming studies are presented in Appendix A. For norming study 1, we enrolled 14 participants in the younger-old cohort $(M=60.6$ years $)$ and 13 in the older-old cohort $(M=75.5$ years), with an overall mean participant age of 67.7 years. For norming study 2, we again recruited participants into a younger-old cohort $(\mathrm{N}=17, \mathrm{M}=58.4$ years $)$ and an olderold cohort $(\mathrm{N}=13, \mathrm{M}=78.4$ years), with an overall mean participant age of 67.1 years. Materials

Test sets were based on Kamide et al. (2003) in which sentence sets included two agents and two verbs, yielding four agent-verb combinations and thus four target objects. Following Borovsky et al. (2012), stimuli sets were designed such that each object served once as the target, 
once as an agent-related distractor, once as a verb-related distractor, and once as an unrelated distractor so that items were fully counterbalanced across the study:

The fireman rides the truck / bike / hamburger / candy. The fireman tastes the hamburger / candy / truck / bike. The girl rides the bike / truck / candy / hamburger. The girl tastes the candy / hamburger / bike / truck.

In norming study 1 , we tested 32 items ( 8 base sentences x 4 different agent-verb combinations) reported by Borovsky et al. (2012) and augmented those with 32 additional items developed using norms from McRae et al. (https://sites.google.com/site/kenmcraelab/normsdata). We extracted all possible agent-verb, verb-target, and agent-target pairs from the sentence items. In norming study 1 , each participant rated a total of 452 word pairs that were isolated from their sentence contexts (128 agent-target, 179 verb-target, 145 agent-verb). Based on its role in the stimulus set, each pairing was designated as either a "target" pairing (e.g. fireman-truck, rides-truck) or a "distractor" pairing (e.g. fireman-bike, rides-hamburger). In norming study 2, additional novel test stimuli were created in a similar fashion to replace problematic stimuli/targets/distractors identified in Norming Study 1. In Norming Study 2, distractor fillers were added to the agent-verb survey, which otherwise would have contained only target pairings, resulting in a total of 744 items (281 agent-target pairs, 337 verb-target pairs, and 126 agent-verb pairs).

\section{Procedure}

Target objects were not necessarily required to be maximally predictable from the linguistic context because participants viewed a constrained set of four images representing the potential targets of each sentence. Target objects instead needed to be rated as significantly more probable than their on-screen distractor object counterparts. Therefore, to capture the relative 
strengths of association for high- and low-probability items, participants rated preselected targets using a Likert scale (rather than providing continuations in an open-ended cloze task).

Participants completed the norming study using the survey function in Qualtrics on a lab computer (Norming Study 1) or using their home computer (Norming Study 2). In Norming Study 1, participants completed the experimental blocks in a fixed order: agent-verb, agenttarget, then verb-target. Questions were presented in randomized order within these blocks. However, for the agent-verb and verb-target surveys, individual items featuring the same verb were grouped together to facilitate rapid judgments. The survey questions asked participants to rate "how common" it is for various types of objects or people in the world to: "engage in various activities" (agent-verb), "participate in a single scenario" (agent-target), or to "have various actions performed on them, or performed to them" (verb-target). Participants rated the items on a scale of 1 (least common/likely) to 7 (most common/likely). Before each block, participants were given example items and ratings. Participants were instructed to provide their first impression of each object, and to use the numbers 2-6 for pairings that they believed fell between the two extremes. In norming study 2, test items were split into a form A version (338 items) and a form B version (406 items). Fifteen participants completed each form version. Study 1 revealed potential evidence of rating-fatigue, with polarized ratings for the verb-target block compared to earlier blocks, resulting in the decision to administer two form versions in the second norming study given the larger number of test items. In both norming studies, the typical time for survey completion was 45-80 minutes.

\section{Results}

In norming study 1 , target pairings were rated significantly higher (more typically related) than distractor pairings (targets' mean $=6.19$, mean $\mathrm{SD}=.93$; distractors' mean $=2.24$, mean $\mathrm{SD}=1.11$; Welch's t-test $p<.0001) .75 .2 \%$ of individual item pairs fell within 1.5 points 
of the ideal value (i.e., between 5.5-7 for target item pairings and between 1-2.5 for distractor item pairings). However, all but one of the sentence test sets contained at least one component that was rated outside of these ranges. Typically, these poorly fitting items were distractors that were rated as being overly associated with agents/verbs that they were not intended to fit. Additionally, distractor pairs were occasionally rated higher than their counterpart target pairs. For example, the intended target pair fireman-hamburger received a mean rating of only 2.96, compared to a 5.33 rating for the proposed distractor pair girl-hamburger. In norming study 2, target pairings were again rated significantly higher than distractor pairings (targets' mean $=$ 5.88, mean $\mathrm{SD}=1.09$; distractors' mean $=2.29$, mean $\mathrm{SD}=1.12$, Welch's t-test $p<.0001$ ).

From the pool of all normed items (Study 1 and Study 2 combined), 12 sentence stimuli sets (48 sentences in total) were selected for the visual world paradigm experiment based on the ratings and the availability of suitable images for the target objects. Each target pair in the final set of sentence stimuli was rated higher than all corresponding distractor pairs (final targets' mean $=6.30$, mean $\mathrm{SD}=.87$; final distractors' mean $=1.68$, mean $\mathrm{SD}=.95$, Welch's t-test $p<$ .0001). Individual item ratings for the final stimulus items are publicly available at doi:10.18131/g3-6r76-cq21 (Roberts \& Aveni, 2020), and motion content ratings are publicly available at doi:10.18131/g3-aran-nz90 (Roberts \& Aveni, 2021).

In norming study 1 , we additionally assessed whether the obtained norms were equally valid for participants of varying ages and MoCA scores. Participants' mean distances from others' ratings were $0.69 z$ on average. Variability in item ratings correlate significantly with age (Pearson's $r=0.03, p=0.877$ ), suggesting that the norms are equally valid for younger-old and older-old participants. With the exclusion of one outlier participant, there was also no significant correlation between variability in item ratings and MoCA scores (Pearson's $r=-0.31, p=.127$ ). 
The lack of an effect of MoCA scores suggests that the norms are equally valid in participants with fully intact cognition as in participants with scores borderline for mild cognitive impairment (MCI). These analyses were conducted using the cor.test() function in R version 3.5.1.

\section{Motion content norming study}

Once the 48 stimulus sentences were selected, a third norming study was conducted to quantify the degree of motion content of each selected verb. Participants for the motion content norming study consisted of a convenience sample of 20 healthy adults who primarily spoke English and were $18-42$ years old $($ mean $=24.10, \mathrm{SD}=5.66)$. For this study, also conducted via Qualtrics, participants were instructed to "rate how much movement would typically be used to complete each of the following actions" using a 1-7 Likert scale. When rating items' motion content, participants asked to consider the indicated verb sense (e.g., rock [cause to move back and forth or side to side]). Mean ratings for each verb were used to classify items as 'low' $(<4)$ or 'high' (>4) motion content in subsequent motion content eye tracking analyses, resulting in 13/48 sentences being designated as 'high' motion content.

\section{Experiment: anticipatory eye movements during sentence comprehension}

We assessed PD and control participants' prediction of patients (target objects) from the combination of an agent and a verb. Performance in this task was contrasted with performance on baseline sentences (Look at the [bathtub]), which did not require use of combinatory semantics.

\section{Participants}

Participants were recruited using methods identical to those in norming study 1 . In addition to the eligibility requirements for the norming studies, participants were required to have an in-person MoCA score of 24 or higher (reflecting an optimised cut-off score for individuals with PD; Hoops et al., 2009). Participants also were required to have sufficient vision 
to read the instructions and view the images used in the study on the display monitor $(\geq 20 / 50$ vision, either corrected or uncorrected), not to have cataracts, and were required to have a pure tone audiometric average $\leq 40 \mathrm{~dB} \mathrm{HL}$ bilaterally at 500, 1000, and $2000 \mathrm{~Hz}$, reflecting normal or only mildly impaired hearing. All PD participants had been diagnosed for a minimum of one year and were under the care of a movement disorders neurologist. Except for one de novo participant, all PD participants were on stable PD medication. Additionally, participants were excluded during the screening stage if the experimenter could not obtain reliable calibration for eye-tracking.

In total, 50/80 screened participants met all criteria and were enrolled. Two participants (one control and one with PD) were excluded after study completion but before data analysis due to poor-quality eye-tracking data. Poor-quality data was operationally defined as having $>15 \%$ of trials removed due to track loss, coupled with a relative lack of fixations on target objects (reflecting lack of engagement with the task). The final analysis included 24 control participants (16 female, 8 male) and 24 participants with PD (11 female, 13 male). Table 1 includes demographic data for both the PD and control groups. There were no significant differences between groups on age, years of education, audiometric pure tone average, MoCA, or geriatric depression scale scores. The Unified Parkinson's Disease Rating Scale (Goetz et al., 2008) and Hoehn and Yahr (Goetz et al., 2004) scores suggest that the PD cohort comprised mainly participants with relatively mild disease.

\section{General study procedures}

In most cases, participants completed the study in two visits, within a 7- to 10-day window. When participants had current neuropsychological assessment data available from our lab (within 6 months of the eye-tracking experiment) we reduced study burden and preserved assessment fidelity by using those existing assessment data ( $\mathrm{N}=10 \mathrm{PD} ; 1$ control). In these 
cases, participants completed only a single study visit. Participants with PD completed the experiment in "on" medication state. While day to day fluctuations are common in PD, testing at the same time of day ensured participants were medicated at similar levels during both their testing sessions. Study visit 1 typically included the screening and neuropsychological assessment, which lasted approximately 2 hours. Study visit 2 typically included the eye-tracking tasks, which lasted approximately 1 hour.

\section{Neuropsychological assessment}

A detailed description of each test and the domains assessed is presented in Appendix B. Tests were administered by a single examiner and were administered according to protocols outlined in published procedural manuals. Assessment sessions were audio/video recorded for doublescoring and fidelity procedures. Disagreements in test scoring were resolved through consensus procedures. Neuropsychological test data are presented in Table 1. The absence of dementia was confirmed neuropsychologically with all participants being independent in activities of daily living, and with none scoring below 2 SD on any cognitive test. Three control participants and one PD participant scored $>1.5$ but $<2$ SD below normal limits on multiple tests and thus met criteria for mild cognitive impairment (Litvan et al., 2012). However, these participants met the minimum cognitive screening requirement and showed essentially normal task performance upon visual inspection of the eye-tracking data. Thus, we judged that these participants' cognitive impairment was mild enough not to significantly interfere with participants' ability to complete the task, and so they were not excluded from analysis. Descriptive and inferential statistics for the neuropsychological tests were calculated using the mean(), sd(), and t.test() functions in $\mathrm{R}$ version 3.6.0.

(Table 1 about here) 


\section{General eye-tracking method}

Eye movements were recorded monocularly using a desktop-mounted SR Research Eyelink $1000+$ camera set to record at a sampling rate of $1000 \mathrm{~Hz}$. Participants were seated with their eyes approximately $57 \mathrm{~cm}$ from the monitor and $52 \mathrm{~cm}$ from the camera with their heads stabilized using a SR Research chinrest. The computer was set to its native resolution of $1920 \mathrm{x}$ 1080 and the use portion of the screen was adjusted to $30.5 \mathrm{~cm}$ horizontally and $25.4 \mathrm{~cm}$ vertically, resulting in 29.9 (width) $\times 25.1$ (height) degrees of visual angle to accommodate the participant-monitor distance. The remaining portion of the screen was blacked out both during the experimental trials and calibration to keep luminosity consistent and to minimize inaccurate calibration due to changes in pupil size. Calibration and validation area proportions were adjusted accordingly. Experimental stimuli were presented using Experiment Builder, Version 2.1.140 software. Calibration and validation procedures were performed before each experimental block and whenever the participant moved their head and calibration became inaccurate (detected automatically at the beginning of each trial). Eyelids sometimes obscure the pupil, particularly in older adults (Friedman, 2005), and this can lead to track loss when pupils are tracked via the centroid method (SR Research "EyeLink 1000 User Manual," 2010). Therefore, pupils were tracked via the ellipse method for all participants.

We used color images of each of the target objects in both predictive and non-predictive trials to enhance recognizability (Rossion \& Pourtois, 2004). All sentences were recorded in an ANSI-standard audiometric testing booth by a native Midwestern American English male speaker. Recordings were made in $44.1 \mathrm{kHz}$ sampling rate and mono format using an AKG C 520 head-mounted condenser microphone connected to a laptop via a SoundDevices USBPre 2 pre-amplifier. See Appendix C for additional detail on image selection, audio recording, audio stimuli selection, and editing procedures. 
Each eye-tracking session began with a comfortable listening level task to ensure stimulus audibility given the increased risk of hearing impairment in older adults. Participants heard a practice list of words, and the experimenter raised or lowered the volume progressively, introducing new lists of phonologically similar practice words, until a volume level was reached where $100 \%$ of words were repeated accurately and/or the participant indicated that the volume could no longer be increased without becoming uncomfortably loud.

\section{Visual World Paradigm procedures}

To address Aim 1, participants listened to predictive sentences in a visual world paradigm task. In the predictive sentence condition, the agent was more associated with the target object and an agent-based distractor object than with the verb-based and unrelated distractors. The verb was more associated with the target object and a verb-based distractor object than with the agentbased and unrelated distractors.

However, interpretation of group differences in anticipatory looks to target objects can be accounted for by factors unrelated to predictive processes, such as systematic group differences in saccadic latencies or systematic issues with the prerequisite steps of quickly identifying pictured objects, maintaining objects' locations, and rapidly comprehending simple spoken sentences. Therefore, we also included a baseline sentence condition modeled on Santerre et al. (2015) that included sentences in the form Look at the [target]. Null group effects on the baseline condition would argue against these alternative interpretations, allowing more robust conclusions regarding the role of language prediction on the predictive sentence condition. The two conditions were presented in a fixed order with the baseline sentence condition following the predictive sentences for all participants. 
Visual Stimuli. A schematic of the eye tracking task from the participant's perspective is shown in Figure 1 below. In order to moderate visual bias that would potentially obscure predictive eye movements, we allowed a 2000 millisecond preview period.

(Figure 1 about here)

Sentence stimuli. Each stimulus set contained four sentences, with each image serving once as the target object, once as an agent-related distractor, once as a verb-related distractor, and once as an unrelated distractor. Each participant saw the same stimuli. However, the order of sentences was pseudorandomized into ten different pre-determined trial orders using a random number generator. When necessary, items were rearranged manually to prevent the target object from appearing in the same quadrant of the screen on more than two consecutive trials and to prevent sentences from the same set appearing consecutively (e.g., The fisherman rocks the boat could not be followed by The grandmother rocks the cradle). There were 8 practice trials and 48 experimental trials of this sentence type (Appendix D; high motion content sentences marked ' $\left.H^{\prime}\right)$.

Baseline sentence stimuli were presented in a single block at the end of the eye tracking session, following all predictive sentences, so that the differing task directions would not influence participants' performance on predictive sentences. Baseline sentences followed the same randomization procedures as the predictive trials. During each of these trials, participants viewed four objects that were phonologically and semantically unrelated to each other and that were not present in the prediction trials. Items were balanced so that each object appeared three or four times. In addition, each trial contained at least one object that was never used as the target object. This was done to minimize participants' ability to predict the target object by ignoring 
objects that had been the target of previous sentences. There were 5 practice trials and 20 experimental trials featuring baseline sentence stimuli (Appendix E).

Attention questions. To ensure that participants were attending to the sentences, attention check questions were added at randomly chosen intervals throughout the predictive trials (2 questions during practice items, 12 in experimental items). Questions were manually re-arranged as needed to appear at least two sentences apart. During these comprehension question trials; participants saw a single word on-screen along with the prompt: Say "YES" if you heard this word in the last sentence: [word]. Otherwise, do not say anything. Words that had not appeared in the most recent trial also did not appear anywhere else in the experimental sentences, making it relatively easy for participants to identify the unused words. Participants answered all questions correctly except for one participant, who responded to two of the questions by repeating the onscreen word but otherwise answered all questions correctly. There were no such questions for the nonpredictive sentences.

Instructions. Instructions for the predictive sentence blocks were presented simultaneously verbally and onscreen as follows: "You will hear a sentence and see four images on the screen. Pay attention to the sentence and the pictures. You may look around the images freely. Sometimes we will ask you whether you heard a certain word in the last trial. When this happens, if you just heard that word, say yes. If you did not just hear that word, please wait quietly." Instructions for the baseline sentences were presented verbally and onscreen as follows: "You will see a display with four pictures while hearing a sentence. Look at whatever picture you are told to look at. We will not ask you any questions."

Pre-processing of eye-tracking data. Data were exported using the sample report in EyeLink Data Viewer software package (SR Research Ltd., version 3.2.48) and thus included both longer 
fixations and shorter fixations broken up by saccades. The eye-tracking data were pre-processed using a custom script in $\mathrm{R}$ (version 3.6.0) that made extensive use of the eyetracking $R$ package (version 0.1.8; Dink \& Ferguson, 2015). This custom script first created the track loss and interest area columns required for analysis in eyetracking $R$ and selected rows pertaining to the trial type(s) of interest. Fixations outside of the four interest areas were excluded from analysis. The eyetrackingR package was used to subset the data into agent-only, verb-only, and target-only analysis windows for the predictive trials and a target-only window for the non-predictive trials. To account for saccade programming time, all time windows were created with a 200ms delay from the auditory onset of the relevant word (Matin et al., 1993; Saslow, 1967). The data were binned into 50ms intervals, so time windows were extended or truncated slightly as needed to avoid creating bins with systematically fewer samples. For the predictive trials (Aim 1), the beginning of the agent window was extended $24 \mathrm{~ms}$ into the first article, the end of the verb window was extended $37 \mathrm{~ms}$ into the second article, and the end of the target object window was truncated by $4 \mathrm{~ms}$. For the non-predictive trials (Aim 2), the end of the target object window was extended by $25 \mathrm{~ms}$.

EyetrackingR functions were also used to assess and to remove trials with $25 \%$ or more track loss during the full sentence duration (Dink \& Ferguson, 2016) and to calculate proportions of fixations on each interest area for each $50 \mathrm{~ms}$ time bin in the analysis windows. In $27.7 \%$ of predictive trials and $25.1 \%$ of non-predictive trials, participants were already fixating the target image just prior to sentence onset. Because the present study intended to examine only agent-, verb-, and target-driven increases in fixations on target objects, these target-anticipated trials were removed from the analysis. Although this resulted in substantial data loss, this percentage loss was in line with that of similar studies (Arai \& Keller, 2013; Barr et al., 2011). This removal 
also helped ensure that participants' eye movements reflected naïve predictions based on the words in the sentences rather than predictions based on the study structure. In addition, as detailed below in the results, repeating these same analyses with target-anticipated trials included resulted in only minimal changes to the model fit, and no change to the pattern of findings between PD and control participants. Following removal of target-anticipated trials and trials with excessive track loss, the mean number of predictive trials remaining was $33.06 \pm 3.37 \mathrm{SD}$.) The mean number of non-predictive trials remaining was $13.21 \pm 2.71 \mathrm{SD}$ ). Analysis of eye-tracking data. The eye-tracking observations used across all study aims were nested within participants and therefore did not meet the independent samples assumption for ANOVAs. Instead, the cleaned, subsetted eye-tracking data were fitted to a series of logistic mixed effects (multi-level) models using the glmer command in the R package lme4 (version 1.1-21, Bates et al., 2015). All intermediate proportions of fixations on each interested area were rounded to either 0 (no fixation) or 1 (fixation) because the raw binned proportions essentially followed a binomial distribution. Therefore, rather than predicting these proportions, our models predict the odds ratio of fixations on the target versus fixations on all other distractors. This odds ratio is log-transformed into "logits" of fixations on each interest area. In addition, each clustering unit (e.g., participant) is permitted to have its own intercept, and in many cases, its own slope term as well. The fixed effects estimates are drawn from the average of these individual intercepts and slopes. The random effects characterize the degree of difference across individual intercepts and slopes.

For each time window of interest, we tested for significant differences in proportions of fixations on the target object over time, by group, and for group by time interactions (which represent differential effects of group on rate of increase in fixations on the target). To avoid 
collinearity issues in our assessment of time effects, we used the orthogonal time polynomials generated by the eyetrackingR package instead of natural time polynomials (Mirman et al., 2008). As a result, intercept values reflect mean values rather than values at $t=0$. Linear term estimates indicate whether fixation proportions increase, decrease, or remain flat between the beginning and end of the analysis window. Finally, the quadratic term estimates indicate whether fixation proportions change at a constant rate or a changing rate. In each model, we additionally generated random intercepts and random linear slopes for subjects (to assess individual differences) and for items (to assess stimulus-driven variability). Random quadratic slopes for subjects and items were included only when they did not cause singular model fits (overfitting). Random effects were estimated with an unstructured covariance matrix.

For predictive sentences, we modeled fixations on the target object in separate logistic models for three time windows of interest: the agent window, the verb window, and finally the target window. We additionally modeled the effect of group on fixations on the verb-related distractor object. We then performed additional analyses designed to explore the role of the motion content of the stimuli and of PD participants' motor abilities on fixations to the target object. Specifically, we modeled the effect of motion content (and its interactions with group) in the agent, verb, and target time windows. For the non-predictive sentences, we modeled only fixations on the target during the target window, following the spoken instruction "Look at the _." Group and motion content factors were both sum-coded (control -0.5, PD +0.5; lowmotion -0.5 , high-motion +0.5$)$. 


\section{Results and discussion}

\section{Predictive sentences}

Graphical results for the predictive sentences are presented in Figure 2, followed by statistical results for each analysis window.

(Figure 2 about here)

\section{Fixations on the target object}

See Table 2 for statistical results. In each analysis window (agent, verb, and target), the linear term was significant and positive, indicating that fixations on the target object increased throughout the predictive sentences. For the agent window, proportions of fixations on the target object were artificially low at the beginning of the time window because we excluded trials that began with participants fixating the target object. Thus, the true degree of agent-driven increase is somewhat obscured by regression to the mean (Barr et al., 2011). Even so, by the end of the agent window, the proportion of fixations on the target interest area increased to approximately $36.1 \%$, significantly higher than chance $(\chi 2(1564)=102.88, p<.0001)$, reflecting true prediction of the target object beyond mere regression to the mean. The significant linear increase in proportions of fixations on the target object during the verb window reveals successful prediction of the target object, although target fixations did not peak until the target window. Significant negative curvature in proportion of fixations on the target was observed only for the agent and target windows, indicating that the proportion of fixations on the target objects levelled off at the ends of these windows. In contrast, the proportion of fixations on the target object rose steadily throughout the verb window.

There were no significant group differences in the intercept (mean), linear, or quadratic term in any analysis window. Thus, PD and control participants' proportion of fixations and rate of increase in fixations on the target object were essentially the same as controls' throughout the 
predictive sentences, including during the critical verb window, the point at which the target object was uniquely predictable by combining agent and verb thematic fit information.

(Table 2 about here).

Because participants would be expected to fixate the target object approximately $25 \%$ of the time by chance alone, fixations on the target object upon sentence onsets may have been largely "naïve," and thus these trials were arguably of interest to include. However, the pattern of findings did not substantially change when these analyses were re-conducted with targetanticipated trials included rather than removed. All main effects and interactions involving group remained non-significant. Significance statistics related to the overall shape of the curve changed in the following minor ways: 1) for the agent window, the quadratic term became non-significant $(p=.055)$ due to the higher starting position of fixations on the target object, and 2$)$ for the target window, the quadratic term became significant only at the $p<.01$ level, rather than at the $p<$ .001 level.

\section{Fixations on the verb-related distractor}

We conducted post-hoc analyses to assess the significance of the apparent "bump" in fixations on the verb-related distractor towards the end of the predictive sentences. The agent, verb, and target windows described above were chosen based on expected patterns in gaze towards the target object specifically. Thus, they were not optimal for analyzing fixations on the verb-related distractor, which peaked approximately in the time region in between the verb and target windows. We therefore modeled a new combined time window spanning the onset of the verb through the offset of the target when analyzing the proportion of fixations on the verb-related distractor.

There was a significant negative effect of quadratic time (Estimate $=-1.099, S E=0.27, p$ $<0.001)$ but no effect of linear time (Estimate $=-0.616, S E=0.35, p=0.08$ ) on fixations on the 
verb-related distractor. This pattern suggests that fixations on the verb-related distractor rose briefly but significantly before returning to their original low level. Yet there were no significant group differences on the intercept (Estimate $=-0.042, S E=0.20, p=0.84)$, linear term $($ Estimate $=0.114, S E=0.55, p=0.84)$, or quadratic term $($ Estimate $=-0.547, S E=0.34, p=0.11)$.

Therefore, as with proportion of fixations on the target object, PD and control participants did not differ in their patterns of fixations on the verb-related distractor object.

(Figure 3 about here)

\section{Effect of motion content and motor abilities on fixations on the target}

Using the motion content ratings obtained from healthy younger adults, we modeled the effect of motion content and its interactions with group in the agent, verb, and target time windows (see Table 3 for statistical results). Findings relating to the shape of the curve did not change. There were significant linear increases in looks to the target across all time windows and significant negative quadratic terms for the agent and target time windows, with no significant main effects of group (PD vs. control). There was also no main effect of motion content on either the intercept, linear, or quadratic term. However, we found significant group x motion content interactions in the agent and target time windows, as illustrated in Figure 3. Specifically, for PD participants but not for control participants, the mean level of fixations on the target object during the agent window (intercept term) was higher during low motion sentences. Additionally, the linear increase in looks to the target object was less steep in high-motion sentences for control participants, whereas PD participants' looks to the target object increased at a similar rate across high- and low-motion sentences.

(Table 3 about here) 


\section{Discussion - predictive sentences}

In light of prior evidence of action and event knowledge impairments in PD, we predicted that PD participants would show impaired on-line sentence processing when required to combine information from an agent and verb to predict the post-verb object. Specifically, we predicted that PD participants would show reduced proportions and rates of increase of fixations on target (patient) objects. However, these predictions were not clearly supported by the results. When all trials were considered, proportions of anticipatory fixations on the target object did not differ in either mean level or rate of increase between PD and control participants. Additionally, within the PD group, motor severity did not predict fixations on the target object during either the verb or target object time window, as might be expected if sentence comprehension impairments in PD are driven largely by degradations in motoric brain regions and action language processing.

The absence of group differences in fixations on the target object during the agent window suggests that both PD and control participants successfully used agent-based (noun) information to predict the two related, likely target objects. This finding is in line with several other studies that have found intact noun processing in PD participants without cognitive impairment (Bocanegra et al., 2017; Bocanegra et al., 2015; Boulenger et al., 2008; Cardona et al., 2013; Fernandino et al., 2013; Rodriguez-Ferreiro et al., 2009). This finding is also in keeping with Santerre (2015), who found intact predictive processing in PD in simple predictive situations.

The verb analysis window was the critical interest period, as we expected group differences to appear when participants had to rapidly integrate multiple sources of semantic information about the agent and the verb to determine which object was the target. If the PD participants had been unable to make use of the semantic information provided by the verb, then their proportion of fixations on the target during the verb window would not have risen above 
their proportion of fixations at the end of the agent window. Thus, if PD participants were unable to use verb semantic information, they would have shown lower proportions of fixations and/or less steep increases in proportions of fixations on the target during the verb window than controls. Instead, the PD participants showed a similar overall level of fixations on the target as controls, as well as similar rates of increase in fixations on the target, suggesting an intact ability to combine agent and verb thematic fit information to predict the target. Additionally, the lack of group differences in the target window suggests that the PD participants were as capable as controls of fixating explicitly named objects.

Because fixations outside of the interest areas were excluded from our analysis, fixations away from the target object were necessarily accompanied by increased proportions of fixations on one or more distractor images. However, fixations on the verb-related distractor object also did not differentiate PD and control groups. Furthermore, the peak in average fixations on the verb-related distractor occurred in the target window for both PD and control participants. Instead of reflecting errored predictive processing, fixations on the verb-related distractor may reflect a delayed "contrast effect" reported previously in healthy adults, in which participants double-check the current target word against a plausible contrasting object (Kamide et al., 2003; Sedivy et al., 1999). Alternatively, these looks to the verb-related distractor may indicate a local, non-predictive thematic priming effect reported previously in healthy adults (Kukona et al., 2011). In the present study, to ensure diversity of agents in each study block, each block included two sentences that had the same verb but different agents. As a side effect of this design choice, towards the end of each block, the verb-related distractor images would have been the targets of prior sentences and possibly highly primed in both participant groups as a plausible alternate target. 
The results comparing participants' processing of high- and low-motion content trials did not match our initial predictions. We predicted that PD participants might be selectively impaired at processing high-motion sentences and would therefore make fewer predictive fixations to the target image in the verb window of the high-motion sentences. Instead, during the end 'target' window of the high-motion sentences, healthy older adults showed a pattern of slower increases in fixations on the target objects, whereas PD participants' fixations were unaffected by the sentences' motion content. This observed insensitivity to items' motion content may reflect an unexpected consequence of or adaptation to Parkinson's disease. It has been suggested that healthy older adults are 'less embodied' than younger adults, having been shown to favor visual processing over bodily factors in a variety of experimental tasks (Costello \& Bloesch, 2017). Similarly, Pickering and Garrod (2013) propose that there are multiple routes available for language prediction, one simple associative and one motor speech simulation route. According to the 'disrupted motor grounding hypothesis,' embodied language processing mechanisms are disturbed in frontostriatal movement disorders such as PD (Birba et al., 2017). Thus, it is possible that our participants with PD may have exhibited a form of accelerated aging or even strategic processing that decreased attention to verbs' motion content and increased PD participants' reliance on spared associative language processing mechanisms that do not rely on action simulation. In contrast, control participants appeared sensitive to the degree of sentences' motion content, even at the cost of delayed or reduced attention to the target items, perhaps because attending to motion content is not overly detrimental to everyday language processing for healthy adults. However, we interpret these results cautiously, considering that this experiment was not designed to compare high- and low-motion content trials. In particular, it is unclear why a significant motion content x group interaction occurred before the onset of the 
verb (during the agent window). This result may have been driven by uncontrolled differences in other psycholinguistic properties of the high-motion sentences or by differences in the order of presentation of these sentences across participants.

\section{Baseline sentences}

Graphical results for the baseline sentences are presented in Figure 4.

(Figure 4 about here)

\section{Fixations on the target window}

Fixations on the target object increased linearly over the course of the target window (Estimate= 3.819, $S E=0.31, p<0.001)$. The quadratic term did not reach significance, suggesting a relatively even rate of increase throughout the target window (Estimate $=0.308, S E=0.16, p=$ 0.06). There were no significant differences in PD compared to control participants on average proportion of fixations on the target (Estimate $=0.034, S E=0.16, p=0.83$ ), on the linear rate of increase in fixations on the target object (Estimate $=0.067, S E=0.43, p=0.88$ ), or on the curvature of proportion of fixations on the target object (Estimate $=-0.200, S E=0.28, p=0.48$ ).

\section{Discussion - baseline sentences}

The lack of a main effect of group indicates that, as predicted, PD participants and healthy older adults did not differ significantly in their average fixations on the target objects while listening to the baseline sentences. Similarly, the lack of any significant group by time interactions shows that the groups had similar rates of increase and acceleration in proportion of fixations on the target, indicating similar processing patterns in these baseline sentences. These findings are consistent with the results from the target window in the predictive sentences, where both groups showed equivalent proportions of fixations on target objects when the targets are named explicitly. They are also consistent with past studies reporting that people with PD demonstrate intact processing of syntactically simple sentences that do not require fine-grained on-line 
processing of semantic goodness of fit (Grossman et al., 1992; Lieberman et al., 1992). The similarity of the obtained PD data to that of healthy adults helps validate the use of eye-tracking to study language comprehension in PD, as it suggests that saccadic behaviors in non-predictive contexts are similar between controls and individuals with PD without cognitive impairment, at least when the areas of interest are approximately $5 \mathrm{~cm}^{2}$ or greater.

\section{Conclusions}

\section{Strengths and limitations}

One strength of the present study is that it featured largely early to mid-stage PD participants who were well characterised and with neuropsychologically-determined absence of dementia. Whereas other studies investigating core action language deficits in PD participants without cognitive impairment have relied largely on cognition screening tools (Bocanegra (Bocanegra et al., 2017; Bocanegra et al., 2015; Boulenger et al., 2008; Garcia et al., 2018), in the present study our stringent criteria increase our confidence in participants' cognitive status.

The experimental design of the present study also provided several advantages. The presence of anomalous sentences in a protocol may disrupt normal processing of low-probability yet plausible items (Matsuki et al., 2011). Furthermore, readers appear to routinely monitor sentences' plausibility whether this monitoring is task-relevant or not (Isberner \& Richter, 2013). Thus, the fact that all of the sentences that participants heard in the present study were semantically plausible is a strength of the study. In addition, many of the distractor objects in the current study fit the sentences reasonably well, albeit at a lower probability than the target object. This design feature meant that participants were often required to detect subtle differences in real-world likelihood rather than attending only to selectional restrictions. Together, these aspects of the study design reinforce our confidence that the findings tested participants' use of 
fine-grained, probabilistic event knowledge. Finally, this study design allowed us to analyze the degree and timing of fixations on distractor images in addition to target images. We replicated previous findings of temporarily increased fixations on the verb distractor during the verb window (Kamide et al., 2003; Kukona et al., 2011) and further showed that this effect did not significantly differ by group.

One limitation of the present study is that we did not carefully control the action content of the verbs used in the predictive sentences. Due to norming and counterbalancing constraints, sentences in the study did not contain exclusively high-motion content items, for which PD participants without cognitive impairment have been hypothesized to show greater impairment. The analysis comparing low- and high-motion sentences addresses this concern, but it is complicated by the fact that 1) there were relatively few high-motion sentences, 2) the ordering of high- vs. low-motion sentences was not controlled during psuedorandomization, and 3) the psycholinguistic properties of high- and low-motion sentence types may have differed on average.

\section{Future directions}

One important direction for future research is to assess language function in PD in a greater range of tasks. Action or event-based language deficits may emerge more prominently in production tasks, or in relatively low-context situations such as confrontation naming or singleword comprehension. Although we did not see group differences in verb confrontation naming in the present study, this is likely attributable to the fact that our participants scored essentially at ceiling on the Northwestern Naming Battery used for the present study. Indeed, studies using other verb naming tests have repeatedly found PD participants to be impaired, particularly for action verbs (Bocanegra et al., 2017; Bocanegra et al., 2015; Cousins et al., 2018; Herrera et al., 2012; Roberts \& Post, 2018; Rodriguez-Ferreiro et al., 2009). Thus, future work should test PD 
participants' language processing abilities in multiple language contexts. Future research should also test whether the finding of PD participants' insensitivity to verbs motion content relative to control participants replicates under more stringent experimental control, and whether this finding may reflect a disruption of embodied language prediction mechanisms in PD and a subsequent shift to reliance on relatively intact, non-embodied mechanisms.

\section{Summary}

The current study sought to determine whether on-line processing of thematic fit, grounded in combinatorial event semantic knowledge, is a source of language impairment in PD. The results did not support our prediction that people with PD without cognitive impairment would differ from controls in combining semantic information to predict target objects, and instead revealed robust on-line prediction effects even in the context of disease that is argued to affect action and event knowledge. In addition, PD participants were not more impaired on highmotion than low-motion sentences, although control participants in our study did show this pattern of reduced fixations on the target objects during high-motion sentences. These findings do not appear to support strong embodied cognition theories, although they may be compatible with theories that predict that brain activity in motor regions will be reduced when processing is supported by context (Grisoni et al., 2016; Pulvermüller, 2018b) and with theories that predict disrupted use of embodied language processing mechanisms in Parkinson's disease (Birba et al., 2017). The present study also contributes additional evidence to the existing literature showing that healthy older adults immediately use semantic information to comprehend sentences.

\section{Acknowledgements}

The authors are grateful to Dr. Jeff Elman for his inspiration and his contributions to the conceptual development of this study, the interpretation of our pilot data, and stimuli selection 
for the final study. We also thank the following individuals Steve Uliana (stimuli audio recordings); Marissa Esparza and Stephanie Gutierrez (data collection); Chelsea Avery, Richard Richter, Stephanie Gutierrez, Richard Martin, and Ashana Torani (stimuli selection and development); Tara Poikey, Jayna Patel, Alexander Havens, Mackenzie Barber, Erin Blaze, Madeleine Chow, Sarah Lawson, and Melanie Davis (double scoring neuropsychological assessments).

\section{Disclosure of interest}

The authors report no conflict of interest.

\section{Data availability statement}

$\mathrm{R}$ packages used in the analysis are publicly available. Data from the norming studies are publicly available at doi:10.18131/g3-6r76-cq21 and doi:10.18131/g3-aran-nz90. Experiment Builder code for delivering the experiment, picture stimuli, and all deidentified data have been archived at the Northwestern University Library and are available by request to the corresponding author.

\section{Funding}

This work was supported by a Parkinson's Canada Pilot Grant to authors KM, MEJ., JAF, and AR. And by gifts from an anonymous donor to MEJ and from Ms. Wendy Schall to AR. 


\section{References}

Alexander, G. E., Delong, M. R., \& Strick, P. L. (1986). Parallel Organization of Functionally Segregated Circuits Linking Basal Ganglia and Cortex. Ann. Rev. Neurosci., 9, 357-381.

Altmann, G. T. M. (1999). Thematic role assignment in context. Journal of Memory and Language, 41(1), 124-145. https://doi.org/10.1006/jmla.1999.2640

Altmann, G. T. M., \& Kamide, Y. (1999). Incremental interpretation at verbs: restricting the domain of subsequent reference. Cognition, 73, 247-264. https://doi.org/10.1016/S00100277(99)00059-1

Altmann, G. T. M., \& Mirković, J. (2009). Incrementality and Prediction in Human Sentence Processing. Cognitive science, 33, 583-609. https://doi.org/10.1111/j.15516709.2009.01022.x

Arai, M., \& Keller, F. (2013). The use of verb-specific information for prediction in sentence processing. Language and Cognitive Processes, 28(4), 525-560. https://doi.org/10.1080/01690965.2012.658072

Ash, S., Jester, C., York, C., Kofman, O. L., Langey, R., Halpin, A., Firn, K., Dominguez Perez, S., Chahine, L., Spindler, M., Dahodwala, N., Irwin, D. J., McMillan, C., Weintraub, D., \& Grossman, M. (2017). Longitudinal decline in speech production in Parkinson's disease spectrum disorders. Brain Lang, 171, 42-51. https://doi.org/10.1016/j.bandl.2017.05.001

Auclair-Ouellet, N., Hanganu, A., Mazerolle, E. L., Lang, S. T., Kibreab, M., Ramezani, M., Haffenden, A., Hammer, T., Cheetham, J., Kathol, I., Pike, G. B., Sarna, J., Martino, D., \& Monchi, O. (2020). Action fluency identifies different sex, age, global cognition, executive function and brain activation profile in non-demented patients with Parkinson's disease. J Neurol. https://doi.org/10.1007/s00415-020-10245-3

Auriacombe, S., Grossman, M., Carvell, S., Gollomp, S., Stern, M. B., \& Hurtig, H. I. (1993). Verbal Fluency Deficits in Parkinson's Disease. Neuropsychology, 7(2), 182-192.

Bak, T. H. (2013). The neuroscience of action semantics in neurodegenerative brain diseases. Curr Opin Neurol, 26(6), 671-677. https://doi.org/10.1097/WCO.0000000000000039

Barr, D. J., Gann, T. M., \& Pierce, R. S. (2011). Anticipatory baseline effects and information integration in visual world studies. Acta Psychol (Amst), 137(2), 201-207. https://doi.org/10.1016/j.actpsy.2010.09.011

Bates, D., Maechler, M., Bolker, B., \& Walker, S. (2015). Fitting Linear Mixed-Effects Models Using lme4. Journal of Statistical Software, 67(1), 1-48. https://doi.org/doi:10.18637/jss.v067.i01

Berg, E., Bjornram, C., Hartelius, L., Laakso, K., \& Johnels, B. (2003). High-level language difficulties in Parkinson's disease. Clinical Linguistics \& Phonetics, 17, 63-80. https://doi.org/10.1080/0269920021000055540

Bicknell, K., Elman, J. L., Hare, M., McRae, K., \& Kutas, M. (2010). Effects of event knowledge in processing verbal arguments. Journal of Memory and Language, 63(4), 489-505. https://doi.org/10.1016/j.jml.2010.08.004

Binder, J. R., \& Desai, R. H. (2011). The neurobiology of semantic memory. Trends in Cognitive Sciences, 15(11), 527-536. https://doi.org/https://doi.org/10.1016/j.tics.2011.10.001

Birba, A., Garcia-Cordero, I., Kozono, G., Legaz, A., Ibanez, A., Sedeno, L., \& Garcia, A. M. (2017). Losing ground: Frontostriatal atrophy disrupts language embodiment in 
Parkinson's and Huntington's disease. Neurosci Biobehav Rev, 80, 673-687.

https://doi.org/10.1016/j.neubiorev.2017.07.011

Bocanegra, Y., Garcia, A. M., Lopera, F., Pineda, D., Baena, A., Ospina, P., Alzate, D., Buritica, O., Moreno, L., Ibanez, A., \& Cuetos, F. (2017). Unspeakable motion: Selective actionverb impairments in Parkinson's disease patients without mild cognitive impairment. Brain Lang, 168, 37-46. https://doi.org/10.1016/j.bandl.2017.01.005

Bocanegra, Y., Garcia, A. M., Pineda, D., Buritica, O., Villegas, A., Lopera, F., Gomez, D., Gomez-Arias, C., Cardona, J. F., Trujillo, N., \& Ibanez, A. (2015). Syntax, action verbs, action semantics, and object semantics in Parkinson's disease: Dissociability, progression, and executive influences. Cortex, 69, 237-254. https://doi.org/10.1016/j.cortex.2015.05.022

Bornkessel, I., \& Schlesewsky, M. (2006). The extended argument dependency model: a neurocognitive approach to sentence comprehension across languages. Psychol Rev, 113(4), 787-821. https://doi.org/10.1037/0033-295X.113.4.787

Borovsky, A., Elman, J. L., \& Fernald, A. (2012). Knowing a lot for one's age: Vocabulary skill and not age is associated with anticipatory incremental sentence interpretation in children and adults. J Exp Child Psychol, 112(4), 417-436. https://doi.org/10.1016/j.jecp.2012.01.005

Boulenger, V., Mechtouff, L., Thobois, S., Broussolle, E., Jeannerod, M., \& Nazir, T. A. (2008). Word processing in Parkinson's disease is impaired for action verbs but not for concrete nouns. HAL. https://doi.org/10.1016/j.neuropsychologia.2007.10.007

Cardona, J. F., Gershanik, O., Gelormini-Lezama, C., Houck, A. L., Cardona, S., Kargieman, L., Trujillo, N., Arevalo, A., Amoruso, L., Manes, F., \& Ibanez, A. (2013). Action-verb processing in Parkinson's disease: new pathways for motor-language coupling. Brain Struct Funct, 218(6), 1355-1373. https://doi.org/10.1007/s00429-013-0510-1

Chall, J. S., Roswell, F. G., Curtis, M. E., \& Strucker, J. (2003). Quick adult reading inventory. In: Elizabethtown, PA: Continental Press, Inc.

Colman, K. S., Koerts, J., van Beilen, M., Leenders, K. L., Post, W. J., \& Bastiaanse, R. (2009). The impact of executive functions on verb production in patients with Parkinson's disease. Cortex, 45(8), 930-942. https://doi.org/10.1016/j.cortex.2008.12.010

Copland, D. A. (2003). The basal ganglia and semantic engagement: potential insights from semantic priming in individuals with subcortical vascular lesions, Parkinson's disease, and cortical lesions. J Int Neuropsychol Soc, 9(7), 1041-1052. https://doi.org/10.1017/S1355617703970081

Copland, D. A., Chenery, H. J., \& Murdoch, B. E. (2000a). Processing lexical ambiguities in word triplets: Evidence of lexical-semantic deficits following dominant nonthalamic subcortical lesions. Neuropsychology, 14(3), 379-390. https://doi.org/10.1037/08944105.14.3.379

Copland, D. A., Chenery, H. J., \& Murdoch, B. E. (2000b). Understanding Ambiguous Words in Biased Sentences: Evidence of Transient Contextual Effects in Individuals with Nonthalamic Subcortical Lesions and Parkinson's Disease**A portion of the preliminary data from this manuscript was presented at the Academy of Aphasia, 37th Annual Meeting, Venice, Italy, October 25, 1999. Cortex, 36(5), 601-622. https://doi.org/10.1016/s0010-9452(08)70541-0

Copland, D. A., Chenery, H. J., \& Murdoch, B. E. (2001). Discourse Priming of Homophones in Individuals with Dominant Nonthalamtic Subcortical Lesions, Cortical Lesions and 
Parkinson's Disease. Journal of clinical and experimental neuropsychology, 23(4), 538556. https://doi.org/10.1076/jcen.23.4.538.1233

Costello, M. C., \& Bloesch, E. K. (2017). Are Older Adults Less Embodied? A Review of Age Effects through the Lens of Embodied Cognition. Front Psychol, 8, 267. https://doi.org/10.3389/fpsyg.2017.00267

Cotelli, M., Borroni, B., Manenti, R., Zanetti, M., Arevalo, A., Cappa, S. F., \& Padovani, A. (2007). Action and object naming in Parkinson's disease without dementia. Eur J Neurol, 14(6), 632-637. https://doi.org/10.1111/j.1468-1331.2007.01797.x

Cousins, K. A. Q., Ash, S., \& Grossman, M. (2018). Production of verbs related to body movement in amyotrophic lateral sclerosis (ALS) and Parkinson's Disease (PD). Cortex, 100, 127-139. https://doi.org/10.1016/j.cortex.2017.08.030

Crescentini, C., Mondolo, F., Biasutti, E., \& Shallice, T. (2008). Supervisory and routine processes in noun and verb generation in nondemented patients with Parkinson's disease. Neuropsychologia, 46(2), 434-447. https://doi.org/10.1016/j.neuropsychologia.2007.08.021

Dauer, W., \& Przedborski, S. (2003). Parkinson's Disease: Mechanisms and Models. Neuron, 39 , 889-909. https://doi.org/10.1016/S0896-6273(03)00568-3

DeLong, K. A., Urbach, T. P., \& Kutas, M. (2005). Probabilistic word pre-activation during language comprehension inferred from electrical brain activity. Nat Neurosci, 8(8), 11171121. https://doi.org/10.1038/nn1504

Dink, J. W., \& Ferguson, B. (2015). eyetrackingR: An R Library for Eye-tracking Data Analysis. http://www.eyetrackingr.com

Dink, J. W., \& Ferguson, B. (2016). Performing a window analysis using eyetrackingR. http://www.eyetracking-r.com/vignettes/window_analysis

Dubois, B., \& Pillon, B. (1997). Cognitive deficits in Parkinson's disease. Journal of Neurology, 244, 2-8. https://doi.org/10.1007/PL00007725

EyeLink 1000 User Manual. (2010). In. Mississauga, Ontario: SR Research Ltd.

Fernandino, L., Conant, L. L., Binder, J. R., Blindauer, K., Hiner, B., Spangler, K., \& Desai, R. H. (2013). Parkinson's disease disrupts both automatic and controlled processing of action verbs. Brain Lang, 127(1), 65-74. https://doi.org/10.1016/j.bandl.2012.07.008

Friedman, O. (2005). Changes associated with the aging face. Facial Plastic Surgery Clinics, 13(3), 371-380. https://doi.org/10.1016/j.fsc.2005.04.004

Gallese, V., \& Cuccio, V. (2018). The neural exploitation hypothesis and its implications for an embodied approach to language and cognition: Insights from the study of action verbs processing and motor disorders in Parkinson's disease. Cortex, 100, 215-225. https://doi.org/10.1016/j.cortex.2018.01.010

Garcia, A. M., Bocanegra, Y., Herrera, E., Moreno, L., Carmona, J., Baena, A., Lopera, F., Pineda, D., Melloni, M., Legaz, A., Munoz, E., Sedeno, L., Baez, S., \& Ibanez, A. (2018). Parkinson's disease compromises the appraisal of action meanings evoked by naturalistic texts. Cortex, 100, 111-126. https://doi.org/10.1016/j.cortex.2017.07.003

Garcia, A. M., Carrillo, F., Orozco-Arroyave, J. R., Trujillo, N., Vargas Bonilla, J. F., Fittipaldi, S., Adolfi, F., Noth, E., Sigman, M., Fernandez Slezak, D., Ibanez, A., \& Cecchi, G. A. (2016). How language flows when movements don't: An automated analysis of spontaneous discourse in Parkinson's disease. Brain Lang, 162, 19-28. https://doi.org/10.1016/j.bandl.2016.07.008 
Garcia, A. M., Sedeno, L., Trujillo, N., Bocanegra, Y., Gomez, D., Pineda, D., Villegas, A., Munoz, E., Arias, W., \& Ibanez, A. (2017). Language Deficits as a Preclinical Window into Parkinson's Disease: Evidence from Asymptomatic Parkin and Dardarin Mutation Carriers. J Int Neuropsychol Soc, 23(2), 150-158. https://doi.org/10.1017/S1355617716000710

Garnsey, S. M., Pearlmutter, N. J., Myers, E., \& Lotocky, M. A. (1997). The Contributions of Verb Bias and Plausibility to the Comprehension of Temporarily Ambiguous Sentences. Journal of Memory and Language, 37, 58-93. https://doi.org/0.1006/jmla.1997.2512

Geyer, H. L., \& Grossman, M. (1994). Investigating the Basis for the Sentence Comprehension Deficit in Parkinson's Disease. J. Neurolinguistics, 8(3), 191-205. https://doi.org/10.1016/0911-6044(94)90026-4

Godbout, L., \& Doyon, J. (2000). Defective representation of knowledge in Parkinson's disease: evidence from a script-production task. Brain Cogn, 44(3), 490-510. https://doi.org/10.1006/brcg.2000.1213

Goetz, C. G., Poewe, W., Rascol, O., Sampaio, C., Stebbins, G. T., Counsell, C., Giladi, N., Holloway, R. G., Moore, C. G., Wenning, G. K., Yahr, M. D., Seidl, L., \& Movement Disorder Society Task Force on Rating Scales for Parkinson's, D. (2004). Movement Disorder Society Task Force report on the Hoehn and Yahr staging scale: status and recommendations. Movement disorders : official journal of the Movement Disorder Society, 19(9), 1020-1028. https://doi.org/10.1002/mds.20213

Goetz, C. G., Tilley, B. C., Shaftman, S. R., Stebbins, G. T., Fahn, S., Martinez-Martin, P., Poewe, W., Sampaio, C., Stern, M. B., Dodel, R., Dubois, B., Holloway, R., Jankovic, J., Kulisevsky, J., Lang, A. E., Lees, A., Leurgans, S., LeWitt, P. A., Nyenhuis, D., Olanow, C. W., Rascol, O., Schrag, A., Teresi, J. A., van Hilten, J. J., LaPelle, N., \& Movement Disorder Society, U. R. T. F. (2008). Movement Disorder Society-sponsored revision of the Unified Parkinson's Disease Rating Scale (MDS-UPDRS): scale presentation and clinimetric testing results. Movement disorders : official journal of the Movement Disorder Society, 23(15), 2129-2170. https://doi.org/10.1002/mds.22340

Grisoni, L., Dreyer, F. R., \& Pulvermüller, F. (2016). Somatotopic Semantic Priming and Prediction in the Motor System. Cereb Cortex, 26(5), 2353-2366. https://doi.org/10.1093/cercor/bhw026

Grisoni, L., Miller, T. M., \& Pulvermüller, F. (2017). Neural Correlates of Semantic Prediction and Resolution in Sentence Processing. J Neurosci, 37(18), 4848-4858. https://doi.org/10.1523/JNEUROSCI.2800-16.2017

Grisoni, L., Tomasello, R., \& Pulvermüller, F. (2021). Correlated Brain Indexes of Semantic Prediction and Prediction Error: Brain Localization and Category Specificity. Cereb Cortex, 31(3), 1553-1568. https://doi.org/10.1093/cercor/bhaa308

Grossman, M. (1999). Sentence Processing in Parkinson's Disease. Brain and Cognition, 40, 387-413. https://doi.org/10.1006/brcg.1999.1087

Grossman, M., Carvell, S., Stern, M. B., Gollomp, S., \& Hurtig, H. I. (1992). Sentence Comprehension in Parkinson's Disease: The Role of Attention and Memory. Brain and Language, 42, 347-384. https://doi.org/10.1016/0093-934X(92)90074-O

Hare, M., Jones, M., Thomson, C., Kelly, S., \& McRae, K. (2009). Activating event knowledge. Cognition, 111(2), 151-167. https://doi.org/10.1016/j.cognition.2009.01.009

Hely, M. A., Morris, J. G., Reid, W. G., \& Trafficante, R. (2005). Sydney Multicenter Study of Parkinson's disease: non-L-dopa-responsive problems dominate at 15 years. Movement 
disorders : official journal of the Movement Disorder Society, 20(2), 190-199. https://doi.org/10.1002/mds.20324

Herrera, E., Rodriguez-Ferreiro, J., \& Cuetos, F. (2012). The effect of motion content in action naming by Parkinson's disease patients. Cortex, 48(7), 900-904. https://doi.org/10.1016/j.cortex.2010.12.007

Hirtz, D., Thurman, D. J., Gwinn-Hardy, K., Mohamed, M., Chaudhuri, A. R., \& Zalutsky, R. (2007). How common are the "common" neurologic disorders? Neurology, 68, 326-337. https://doi.org/10.1212/01.wnl.0000252807.38124.a3

Hoops, S., Nazem, S., Siderowf, A. D., Duda, J. E., Xie, S. X., Stern, M. B., \& Weintraub, D. (2009). Validity of the MoCA and MMSE in the detection of MCI and dementia in Parkinson disease. Neurology, 73, 1738-1745. https://doi.org/10.1212/WNL.0b013e3181c34b47

Huettig, F. (2015). Four central questions about prediction in language processing. Brain Res, 1626, 118-135. https://doi.org/10.1016/j.brainres.2015.02.014

Humphries, S., Klooster, N., Cardillo, E., Weintraub, D., Rick, J., \& Chatterjee, A. (2019). From action to abstraction: The sensorimotor grounding of metaphor in Parkinson's disease. Cortex, 121, 362-384. https://doi.org/10.1016/j.cortex.2019.09.005

Isberner, M.-B., \& Richter, T. (2013). Can readers ignore implausibility? Evidence for nonstrategic monitoring of event-based plausibility in language comprehension. Acta Psychologica, 142(1), 15-22.

Jankovic, J. (2008). Parkinson's disease: clinical features and diagnosis. J Neurol Neurosurg Psychiatry, 79(4), 368-376. https://doi.org/10.1136/jnnp.2007.131045

Kamide, Y., Altmann, G. T. M., \& Haywood, S. L. (2003). The time-course of prediction in incremental sentence processing: Evidence from anticipatory eye movements. Journal of Memory and Language, 49(1), 133-156. https://doi.org/10.1016/s0749-596x(03)00023-8

Kudlicka, A., Clare, L., \& Hindle, J. V. (2011). Executive functions in Parkinson's disease: systematic review and meta-analysis. Movement disorders : official journal of the Movement Disorder Society, 26(13), 2305-2315. https://doi.org/10.1002/mds.23868

Kukona, A., Fang, S. Y., Aicher, K. A., Chen, H., \& Magnuson, J. S. (2011). The time course of anticipatory constraint integration. Cognition, 119(1), 23-42. https://doi.org/10.1016/j.cognition.2010.12.002

Kuperberg, G. R., \& Jaeger, T. F. (2016). What do we mean by prediction in language comprehension? Lang Cogn Neurosci, 31(1), 32-59. https://doi.org/10.1080/23273798.2015.1102299

Landsheer, J. A. (2020). Impact of the Prevalence of Cognitive Impairment on the Accuracy of the Montreal Cognitive Assessment: The Advantage of Using two MoCA Thresholds to Identify Error-prone Test Scores. Alzheimer Dis Assoc Disord, 34(3), 248-253.

Leon-Cabrera, P., Flores, A., Rodriguez-Fornells, A., \& Moris, J. (2019). Ahead of time: Early sentence slow cortical modulations associated to semantic prediction. Neuroimage, 189, 192-201. https://doi.org/10.1016/j.neuroimage.2019.01.005

Lewis, F. M., Lapointe, L. L., Murdoch, B. E., \& Chenery, H. J. (2007). Language impairment in Parkinson's disease. Aphasiology, 12(3), 193-206. https://doi.org/10.1080/02687039808249446

Lieberman, P., Kako, E., Friedman, J., Tajchman, G., Feldman, L. S., \& Jiminez, E. B. (1992). Speech Production, Syntax Comprehension, and Cognitive Deficits in Parkinson's 
Disease. Brain and Language, 43, 169-189. https://doi.org/10.1016/0093934X(92)90127-Z

Litvan, I., Goldman, J. G., Tröster, A. I., Schmand, B. A., Weintraub, D., Petersen, R. C., Mollenhauer, B., Adler, C. H., Marder, K., Williams-Gray, C. H., Aarsland, D., Kulisevsky, J., Rodriguez-Oroz, M. C., Burn, D. J., Barker, R. A., \& Emre, M. (2012). Diagnostic criteria for mild cognitive impairment in Parkinson's disease: Movement Disorder Society Task Force guidelines. Movement disorders : official journal of the Movement Disorder Society, 27(3), 349-356. https://doi.org/10.1002/mds.24893

Marian, V., Blumenfeld, H. K., \& Kaushanskaya, M. (2007). The Language Experience and Proficiency Questionnaire (LEAP-Q): Assessing language profiles in bilinguals and multilinguals. Journal of Speech, Language, and Hearing Research, 50(4), 940-967.

Matin, E., Shao, K. C., \& Boff, K. R. (1993). Saccadic overhead: Information-processing time with and without saccades. Perception \& psychophysics, 53(4), 372-380. https://doi.org/10.3758/BF03206780

Matsuki, K., Chow, T., Hare, M., Elman, J. L., Scheepers, C., \& McRae, K. (2011). Event-based plausibility immediately influences on-line language comprehension. $J$ Exp Psychol Learn Mem Cogn, 37(4), 913-934. https://doi.org/10.1037/a0022964

McCarthy, R., \& Warrington, E. K. (1987). Understanding: A function of short-term memory? Brain, 110, 1565-1578. https://doi.org/10.1093/brain/110.6.1565

McRae, K., Hare, M., Elman, J. L., \& Ferretti, T. (2005). A basis for generating expectancies for verbs from nouns. 33, 1174-1184. https://doi.org/10.3758/BF03193221

McRae, K., Spivey-Knowlton, M. J., \& Tanenhaus, M. K. (1998). Modeling the Influence of Thematic Fit (and Other Constraints) in On-line Sentence Comprehension. Journal of Memory and Language, 38, 283-312. https://doi.org/10.1006/jmla.1997.2543

Mega, M., \& Cummings, J. (2001). Frontal subcortical circuits: anatomy and function.

Middleton, F. A., \& Strick, P. L. (2000). Basal ganglia and cerebellar loops: motor and cognitive circuits. Brain Research Reviews, 31, 236-250. https://doi.org/10.1016/S01650173(99)00040-5

Mirman, D., Dixon, J. A., \& Magnuson, J. S. (2008). Statistical and computational models of the visual world paradigm: Growth curves and individual differences. J Mem Lang, 59(4), 475-494. https://doi.org/10.1016/j.jml.2007.11.006

Moody, T. D., Bookheimer, S. Y., Vanek, Z., \& Knowlton, B. J. (2004). An implicit learning task activates medial temporal lobe in patients with Parkinson's disease. Behav Neurosci, 118(2), 438-442. https://doi.org/10.1037/0735-7044.118.2.438

Moulines, E., \& Charpentier, F. (1990). Pitch-synchronous waveform processing techniques for text-to-speech synthesis using diphones. Speech Communication, 9, 453-467.

Murray, L. L. (2000). Spoken language production in Huntington's and Parkinson's diseases. Journal of Speech, Language, and Hearing Research, 43(6), 1350-1366. https://doi.org/10.1044/jslhr.4306.1350

Nasreddine, D. (2016). MoCA-BLIND. Version 7.1 Original Version. https://www.mocatest.org/paper-tests/moca-test-blind/

Nasreddine, Z. S., Phillips, N. A., Bédirian, V., Charbonneau, S., Whitehead, V., Collin, I., Cummings, J. L., \& Chertkow, H. (2005). The Montreal Cognitive Assessment, MoCA: a brief screening tool for mild cognitive impairment. Journal of the American Geriatrics Society, 53(4), 695-699. https://doi.org/10.1111/j.1532-5415.2005.53221.x 
Péran, P., Rascol, O., Démonet, J. F., Celsis, P., Nespoulous, J. L., Dubois, B., \& Cardebat, D. (2003). Deficit of verb generation in nondemented patients with Parkinson's disease. Movement disorders: official journal of the Movement Disorder Society, 18(2), 150-156.

Perugini, A., Ditterich, J., \& Basso, M. A. (2016). Patients with Parkinson's Disease Show Impaired Use of Priors in Conditions of Sensory Uncertainty. Curr Biol, 26(14), 19021910. https://doi.org/10.1016/j.cub.2016.05.039

Piatt, A. L., Fields, J. A., Paolo, A. M., Koller, W. C., \& Troster, A. I. (1999). Lexical, semantic, and action verbal fluency in Parkinson's disease with and without dementia. J Clin Exp Neuropsychol, 21(4), 435-443. https://doi.org/10.1076/jcen.21.4.435.885

Pickering, M. J., \& Garrod, S. (2013). An integrated theory of language production and comprehension. Behav Brain Sci, 36(4), 329-347. https://doi.org/10.1017/S0140525X12001495

Posner, M., \& Digirolamo, G. (1998). Executive attention: Conflict, target detection, and cognitive control. 401-423.

Pringsheim, T., Jette, N., Frolkis, A., \& Steeves, T. D. (2014). The prevalence of Parkinson's disease: a systematic review and meta-analysis. Movement disorders : official journal of the Movement Disorder Society, 29(13), 1583-1590. https://doi.org/10.1002/mds.25945

Pugh, E. A., Kemp, E. C., van Dyck, C. H., Mecca, A. P., Sharp, E. S., \& Alzheimer's Disease Neuroimaging, I. (2018). Effects of Normative Adjustments to the Montreal Cognitive Assessment. Am J Geriatr Psychiatry, 26(12), 1258-1267. https://doi.org/10.1016/j.jagp.2018.09.009

Pulvermüller, F. (2018a). Neural reuse of action perception circuits for language, concepts and communication. Progress in Neurobiology, 160, 1-44. https://doi.org/https://doi.org/10.1016/j.pneurobio.2017.07.001

Pulvermüller, F. (2018b). Neurobiological Mechanisms for Semantic Feature Extraction and Conceptual Flexibility. Top Cogn Sci, 10(3), 590-620. https://doi.org/10.1111/tops.12367

Pulvermüller, F., \& Grisoni, L. (2020). Semantic Prediction in Brain and Mind. Trends Cogn Sci, 24(10), 781-784. https://doi.org/10.1016/j.tics.2020.07.002

Rayner, K., Warren, T., Juhasz, B. J., \& Liversedge, S. P. (2004). The effect of plausibility on eye movements in reading. J Exp Psychol Learn Mem Cogn, 30(6), 1290-1301. https://doi.org/10.1037/0278-7393.30.6.1290

Roberts, A., \& Aveni, K. (2020). Final_thematic_norms_ratings_ARCHARCHIVED.xls. [Data set]. DigitalHub. Galter Health Sciences Library \& Learning Center. doi:10.18131/g36r76-cq21

Roberts, A., \& Aveni, K. (2021). LCAN_007_motion_content_ratings.xls. [Data set]. DigitalHub. Galter Health Sciences Library \& Learning Center. doi:10.18131/g3-arannz90

Roberts, A., Nguyen, P., Orange, J. B., Jog, M., Nisbet, K. A., \& McRae, K. (2017). Differential impairments of upper and lower limb movements influence action verb processing in Parkinson disease. Cortex, 97, 49-59. https://doi.org/10.1016/j.cortex.2017.09.022

Roberts, A., \& Post, D. (2018). Information Content and Efficiency in the Spoken Discourse of Individuals With Parkinson's Disease. J Speech Lang Hear Res, 61(9), 2259-2274. https://doi.org/10.1044/2018_JSLHR-L-17-0338

Rodriguez-Ferreiro, J., Menendez, M., Ribacoba, R., \& Cuetos, F. (2009). Action naming is impaired in Parkinson disease patients. Neuropsychologia, 47(14), 3271-3274. https://doi.org/10.1016/j.neuropsychologia.2009.07.007 
Rossion, B., \& Pourtois, G. (2004). Revisiting Snodgrass and Vanderwart's object pictorial set: the role of surface detail in basic-level object recognition. Perception, 33(2), 217-236. https://doi.org/10.1068/p5117

Santerre, K. G. (2015). "She will drive the _": Verb-Based Prediction in Individuals with Parkinson Disease (Publication Number 3085) [Master's thesis, University of Western Ontario]. Electronic Thesis and Dissertation Repository.

Saslow, M. (1967). Effects of components of displacement-step stimuli upon latency for saccadic eye movement. Josa, 57(8), 1024-1029. https://doi.org/10.1364/JOSA.57.001024

Schriefers, H., Meyer, A. S., \& Levelt, W. J. M. (1990). Exploring the Time Course of Lexical Access in Language Production: Picture-Word Interference Studies. Journal of Memory and Language, 29, 86-102. https://doi.org/10.1016/0749-596X(90)90011-N

Scott, S. K., \& Johnsrude, I. (2003). The neuroanatomical and functional organization of speech perception. TRENDS in Neurosciences, 26(2), 100-107. https://doi.org/10.1016/S01662236(02)00037-1

Sedivy, J. C., Tanenhaus, M. K., Chambers, C. G., \& Carlson, G. N. (1999). Achieveing incremental semantic interpretation through contextual representation. Cognition, 71, 109-147. https://doi.org/10.1016/S0010-0277(99)00025-6

Siegert, R. J., Taylor, K. D., Weatherall, M., \& Abernethy, D. A. (2006). Is implicit sequence learning impaired in Parkinson's disease? A meta-analysis. Neuropsychology, 20(4), 490495. https://doi.org/10.1037/0894-4105.20.4.490

Trueswell, J. C., Tanenhaus, M. K., \& Kello, C. (1993). Verb-specific constraints in sentence processing: Separating effects of lexical preference from garden-paths. Journal of Experimental Psychology: Learning, Memory, and Cognition, 19(3), 528-553. https://doi.org/10.1037/0278-7393.19.3.528

Warren, T., \& McConnell, K. (2007). Investigating effects of selectional restriction violations and plausibility violation severity on eye-movements in reading. Psychon Bull Rev, 14(4), 770-775. https://doi.org/10.3758/BF03196835

Whiting, E., Copland, D. A., \& Angwin, A. (2005). Verb and context processing in Parkinson's disease. Journal of Neurolinguistics, 18(3), 259-276. https://doi.org/10.1016/j.jneuroling.2004.11.008

Wilson, S. M., Saygin, A. P., Sereno, M. I., \& Iacoboni, M. (2004). Listening to speech activates motor areas involved in speech production. Nat Neurosci, 7(7), 701-702. https://doi.org/10.1038/nn1263

Wu, T., Wang, J., Wang, C., Hallett, M., Zang, Y., Wu, X., \& Chan, P. (2012). Basal ganglia circuits changes in Parkinson's disease patients. Neurosci Lett, 524(1), 55-59. https://doi.org/10.1016/j.neulet.2012.07.012

Zgalijardic, D. J., Borod, J. C., Foldi, N. S., \& Mattis, P. (2003). A Review of the Cognitive and Behavioral Sequelae of Parkinson's Disease: Relationship to Frontostriatal Circuitry. Cognitive and Behavioral Neurology, 16(4), 193-210. 


\section{APPENDICES}

Appendix A

Norming Studies Participant Demographics

\begin{tabular}{|c|c|c|c|}
\hline Variable & 95\% Confidenc & [Lower, Upper] & \\
\hline Study 1 & Younger-old & Older-old & t-tests \\
\hline Age (yrs.) & $\begin{array}{c}\mathbf{6 0 . 6 4}(6.31) \\
{[57.00,64.28]} \\
52-68\end{array}$ & $\begin{array}{c}\mathbf{7 5 . 4 6}(3.84) \\
{[73.14,77.78]} \\
70-80\end{array}$ & $\begin{array}{c}t(25)=-7.30 \\
p<.001\end{array}$ \\
\hline Education (yrs.) & $\begin{array}{c}\mathbf{1 7 . 6 4}(3.27) \\
{[15.75,19.53]} \\
14-27\end{array}$ & $\begin{array}{c}\mathbf{1 7 . 5 8}(2.10) \\
{[16.25,18.92]} \\
13-21.5\end{array}$ & $\begin{array}{c}t(25)=0.05 \\
p=.957\end{array}$ \\
\hline MoCA (/30) & $\begin{array}{c}\mathbf{2 8 . 1 4}(1.41) \\
{[27.33,28.95]} \\
25-30\end{array}$ & $\begin{array}{c}\mathbf{2 6 . 6 2}(1.98) \\
{[25.42,27.81]} \\
23-29\end{array}$ & $\begin{array}{c}t(25)=2.32 \\
p=.029\end{array}$ \\
\hline Study 2 & & & \\
\hline Age (yrs.) & $\begin{array}{c}\mathbf{5 8 . 4 1}(5.96) \\
{[55.34,61.48]} \\
50-67\end{array}$ & $\begin{array}{c}\mathbf{7 8 . 3 8}(5.35) \\
{[75.15,81.62]} \\
70-87\end{array}$ & $\begin{array}{c}t(28)=-9.50 \\
p<.001\end{array}$ \\
\hline Education (yrs.) & $\begin{array}{c}17.94(2.68) \\
{[16.56,19.32]} \\
15-27\end{array}$ & $\begin{array}{c}\mathbf{1 8 . 3 8}(2.27) \\
{[17.02,19.75]} \\
14.5-23\end{array}$ & $\begin{array}{c}t(28)=-0.48 \\
p=.635\end{array}$ \\
\hline $\operatorname{MoCA}(/ \mathbf{1 0 0 \%})$ & $\begin{array}{c}93.94(4.27) \\
{[91.66,96.21]} \\
86.4-100\end{array}$ & $\begin{array}{c}90.70(5.21) \\
{[87.55,90.70]} \\
81.8-96.7\end{array}$ & $\begin{array}{c}t(28)=2.32 \\
p=.077\end{array}$ \\
\hline
\end{tabular}

Note: In study 1, participants' MoCA scores ranged from 23-30, $\mathrm{M}=27.41, \mathrm{SD}=1.85$.

In study 2, participants' MoCA percentage scores ranged from 81.8-100\%, $\mathrm{M}=92.49, \mathrm{SD}=$ 4.91. In the telephone version of the MoCA (norming study 2), a score of $22=$ a score of 30 on the in-person version of the MoCA. 


\section{Appendix B}

Neuropsychological Battery

\begin{tabular}{|c|c|c|c|}
\hline Domain & Task Name & Task Description & Cognitive Skills \\
\hline \multirow{5}{*}{$\begin{array}{l}\text { Executive } \\
\text { Function } \\
\quad \text { and } \\
\text { Attention }\end{array}$} & $\begin{array}{l}\text { D-KEFS Trail Making } \\
\text { Test }^{1}\end{array}$ & $\begin{array}{l}\text { Participants draw a line from number to } \\
\text { letter in ascending order, alternating } \\
\text { between numbers and letters }\end{array}$ & $\begin{array}{l}\text { Visual-motor sequencing } \\
\text { task; task-switching }\end{array}$ \\
\hline & $\begin{array}{l}\text { D-KEFS Color Word } \\
\text { Interference Test }\end{array}$ & $\begin{array}{l}\text { Words written in different colour than word } \\
\text { written. Participants switch between } \\
\text { reading written word and saying font } \\
\text { colour. }\end{array}$ & $\begin{array}{l}\text { Ability to inhibit a } \\
\text { dominant and automatic } \\
\text { verbal response }\end{array}$ \\
\hline & CLOX & $\begin{array}{l}\text { Participants construct an analogical clock } \\
\text { first from memory (CLOX 1), then again } \\
\text { by copying the experimenter's clock } \\
\text { (CLOX 2). }\end{array}$ & $\begin{array}{l}\text { Visuospatial processing } \\
\text { and planning }\end{array}$ \\
\hline & Digit Span & $\begin{array}{l}\text { Participants recite digit spans first forwards } \\
\text { then backwards. }\end{array}$ & $\begin{array}{l}\text { Short-term and working } \\
\text { memory }\end{array}$ \\
\hline & $\begin{array}{l}\text { Semantic Fluency } \\
\text { (Category_animals) }\end{array}$ & $\begin{array}{l}\text { Participants list as many animals as they } \\
\text { can within } 60 \text { seconds }\end{array}$ & $\begin{array}{l}\text { Lexical access; updating } \\
\text { ability }\end{array}$ \\
\hline \multirow{4}{*}{ Language } & 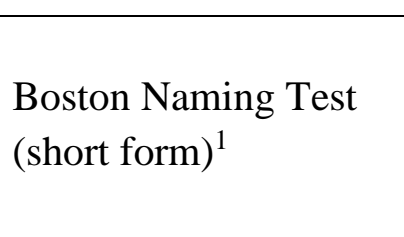 & Noun confrontation naming & $\begin{array}{l}\text { Lexical retrieval of } \\
\text { imageable nouns (high and } \\
\text { low frequency of } \\
\text { occurrence) }\end{array}$ \\
\hline & $\begin{array}{l}\text { Northwestern Naming } \\
\text { Battery }\end{array}$ & $\begin{array}{l}\text { Verb confrontation naming \& } \\
\text { Verb comprehension }\end{array}$ & $\begin{array}{l}\text { Production and } \\
\text { identification of imageable } \\
\text { verbs }\end{array}$ \\
\hline & $\begin{array}{l}\text { Northwestern } \\
\text { Assessment of Verbs } \\
\text { and Sentences }\end{array}$ & $\begin{array}{l}\text { Participants select images that match } \\
\text { spoken sentences of varying syntactic } \\
\text { complexity }\end{array}$ & Sentence comprehension \\
\hline & $\begin{array}{l}\text { Pyramids and Palm } \\
\text { Trees (short form) }{ }^{2}\end{array}$ & $\begin{array}{l}\text { Participants identify which of two objects } \\
\text { "goes with" a target }\end{array}$ & Thematic relatedness \\
\hline \multirow[t]{2}{*}{ Memory } & $\begin{array}{l}\text { Hopkins Verbal } \\
\text { Learning Test }\end{array}$ & Auditory learning of a list of 12 words. & $\begin{array}{l}\text { Verbal learning and } \\
\text { memory }\end{array}$ \\
\hline & $\begin{array}{l}\text { Brief Visuospatial } \\
\text { Memory Test-Revised } \\
\text { (BVMT-R) }\end{array}$ & Visual learning of 6 different designs & $\begin{array}{l}\text { Visuospatial learning and } \\
\text { memory }\end{array}$ \\
\hline
\end{tabular}

*Note: Reference List

${ }^{1}$ Graves, Bezeau, Fogarty, \& Blair, 2004; ${ }^{2}$ Breining...Hillis, 2015 


\section{Appendix C \\ Visual Stimuli Selection and Editing}

Visual stimuli were edited with Adobe Photoshop to normalize the images. For example, words, brand logos, and vibrant patterns were removed; harsh colors including reds or bright blues were toned down in saturation; and where possible, images were placed onto a plain white background with all shadows and reflections were removed. Photos were edited to a uniform size of 400 by 400px. Multiple options were compiled for each object, and a team of voters unfamiliar with the study design identified which images they found most representative of each object.

\section{Word Onsets in Sentence Audio}

The speaker recorded each sentence three times using flat but natural prosody. The selection of these recordings was determined through consensus ratings of three listeners (four raters in cases of a three-way tie) who selected the overall best file based on the sentences' naturalness and lack of audio distortions or interfering noises. We used Praat (Boersma \& Weenink, 2020) to scale the selected sound files to an average intensity of $70 \mathrm{~dB}$. Word onsets and offsets were demarcated in Praat by the first author. Where coarticulation was present, word onsets were marked conservatively, i.e. at the earliest place the next phoneme/word onset was clearly identifiable. Word durations were then manipulated in Praat with a custom script that made use of the overlapadd function to shorten or extend the durations of individual words (Moulines \& Charpentier, 1990). As a result of this manipulation, the onsets of each word in each sentence occurred at a predefined time based on the original mean duration of the agents, verbs, etc. (see below table). For the predictive sentences, we then tested three overall sentence durations and selected the duration that sounded most natural to listeners unfamiliar with the study design. Sound onsets were 
set to $50 \mathrm{~ms}$ across sentence types to allow sufficient time for audio buffering. For predictive sentences, the final speaking rate was 2.63 words per second. For the non-predictive sentences, the final speaking rate was 4.14 words per second, as most words in these sentences were monosyllabic.

\begin{tabular}{|l|r|r|r|r|r|}
\hline \multicolumn{7}{|c|}{ Prediction Trials } \\
\hline & The & [agent] & [verb]s & the & [target] \\
\hline Onset (ms) & 50 & 132 & 708 & 1171 & 1296 \\
\hline Duration (ms) & 82 & 576 & 463 & 125 & 654 \\
\hline \multicolumn{7}{|c|}{ Non-Prediction Trials } \\
\hline
\end{tabular}




\section{Appendix D}

Predictive Sentences Practice

\begin{tabular}{|lllll|}
\hline Sentence & Target & Distractor $\mathbf{1}$ & Distractor 2 & Distractor 3 \\
\hline The maid spreads the blanket. & blanket & broom & icing & cake \\
The hunter loads the rifle. & rifle & antlers & groceries & register \\
The gambler throws the dice. & dice & jackpot & soccer ball & goal \\
The soldier writes the letter. & letter & cannon & experiment & rocket \\
The photographer cleans the camera. & camera & photo & newspaper & typewriter \\
The doctor reads the x-ray. & x-ray & injection & story & assignment \\
The butcher wraps the steak. & steak & scale & candy cane & sleigh \\
The ringmaster trains the lion. & lion & cage & runner & stopwatch \\
\hline
\end{tabular}

Predictive Sentences, Full Trials (Sets 1-12)

\begin{tabular}{|lllll|}
\hline Audio Sentence & $\begin{array}{l}\text { Target } \\
\text { Image }\end{array}$ & $\begin{array}{l}\text { Agent- } \\
\text { related } \\
\text { distractor }\end{array}$ & $\begin{array}{l}\text { Action- } \\
\text { related } \\
\text { distractor }\end{array}$ & $\begin{array}{l}\text { Unrelated } \\
\text { distractor }\end{array}$ \\
\hline $\begin{array}{l}\text { The fisherman sews the net. } \\
\text { The fisherman rocks the boat. }\end{array}$ & bet & boat & quilt & cradle \\
The grandmother rocks the cradle. & cradle & quilt & cradle & quilt \\
The grandmother sews the quilt. & quilt & cradle & net & net \\
The boxer fastens the headgear. & headgear & punching bag & seatbelt & boat \\
The boxer hits the punching bag. $(\mathrm{H})$ & punching bag & headgear & brakes & seatbelt \\
The driver fastens the seatbelt. & seatbelt & brakes & headgear & punching bag \\
The driver hits the brakes. $(\mathrm{H})$ & brakes & seatbelt & punching bag & headgear
\end{tabular}




\begin{tabular}{|c|c|c|c|c|}
\hline The baby drinks the milk. & milk & bib & champagne & heels \\
\hline The baby wears the bib. & bib & milk & heels & champagne \\
\hline The bride drinks the champagne. & champagne & heels & milk & bib \\
\hline The bride wears the heels. & heels & champagne & bib & milk \\
\hline The baker rolls the dough. & dough & oven & sleeping bag & lantern \\
\hline The baker lights the oven. & oven & dough & lantern & sleeping bag \\
\hline The camper rolls the sleeping bag. & sleeping bag & lantern & dough & oven \\
\hline The camper lights the lantern. & lantern & sleeping bag & oven & dough \\
\hline The child catches the football. $(\mathrm{H})$ & football & lollipop & mouse & paw \\
\hline The child licks the lollipop. & lollipop & football & paw & mouse \\
\hline The cat catches the mouse. $(\mathrm{H})$ & mouse & paw & football & lollipop \\
\hline The cat licks the paw. & paw & mouse & lollipop & football \\
\hline The horse eats the carrot. & carrot & fence & fish & waves \\
\hline The horse jumps the fence. $(\mathrm{H})$ & fence & carrot & waves & fish \\
\hline The dolphin eats the fish. & fish & waves & carrot & fence \\
\hline The dolphin jumps the waves. (H) & waves & fish & fence & carrot \\
\hline The policeman closes the cell. & cell & motorcycle & stable & horse \\
\hline The policeman rides the motorcycle. & motorcycle & cell & horse & stable \\
\hline The jockey closes the stable. & stable & horse & cell & motorcycle \\
\hline The jockey rides the racehorse. & horse & stable & motorcycle & cell \\
\hline The lifeguard scans the beach. & beach & swimmer & aisle & money \\
\hline The lifeguard saves the swimmer. (H) & swimmer & beach & money & aisle \\
\hline
\end{tabular}




\begin{tabular}{|c|c|c|c|c|}
\hline The shopper scans the aisle. & aisle & money & beach & swimmer \\
\hline The shopper saves the money. & money & aisle & swimmer & beach \\
\hline $\begin{array}{l}\text { The detective crosses the courtroom. } \\
\text { (H) }\end{array}$ & courtroom & fugitive & jungle & zebra \\
\hline The detective hunts the fugitive. $(\mathrm{H})$ & fugitive & courtroom & zebra & jungle \\
\hline The lion crosses the jungle. $(\mathrm{H})$ & jungle & zebra & courtroom & fugitive \\
\hline The lion hunts the zebra. $(\mathrm{H})$ & zebra & jungle & fugitive & courtroom \\
\hline The mechanic pours the oil. & oil & tools & salt & dishes \\
\hline The mechanic organizes the tools. $(\mathrm{H})$ & tools & oil & dishes & salt \\
\hline The waitress organizes the dishes. $(\mathrm{H})$ & dishes & salt & tools & oil \\
\hline The waitress pours the salt. & salt & dishes & oil & tools \\
\hline The pilot wears the uniform. & uniform & airplane & overalls & tractor \\
\hline The pilot controls the airplane. & airplane & uniform & tractor & overalls \\
\hline The farmer wears the overalls. & overalls & tractor & uniform & airplane \\
\hline The farmer controls the tractor. & tractor & overalls & airplane & uniform \\
\hline The pirate wears the eyepatch. & eyepatch & ship & sunglasses & car \\
\hline The pirate steers the ship. & ship & eyepatch & car & sunglasses \\
\hline The chauffeur wears the sunglasses. & sunglasses & car & eyepatch & ship \\
\hline The chauffer steers the car. & car & sunglasses & ship & eyepatch \\
\hline
\end{tabular}

\section{Appendix E}

Baseline Sentence Practice

\begin{tabular}{|llll|}
\hline Target & Distractor 1 & Distractor 2 & Distractor 3 \\
\hline diamond & hat & flower & beer
\end{tabular}




\begin{tabular}{|llll|} 
guitar & deer & ladder & brick \\
jacket & bow & dog & pine cone \\
banana & pan & umbrella & lightbulb \\
bike & present & mushroom & fork \\
\hline
\end{tabular}

Control Trials

\begin{tabular}{|c|c|c|c|}
\hline Target & Distractor 1 & Distractor 2 & Distractor 3 \\
\hline helmet & clock & balloon & $\log$ \\
\hline drum & bathtub & rope & strawberry \\
\hline tape & strawberry & drum & helmet \\
\hline teapot & fan & brush & drum \\
\hline bathtub & violin & dress & slide \\
\hline lamp & feather & strawberry & truck \\
\hline feather & belt & slide & teapot \\
\hline $\log$ & scarf & fan & tape \\
\hline scarf & violin & teapot & roller skate \\
\hline slide & $\log$ & feather & balloon \\
\hline dress & flashlight & clock & mailbox \\
\hline clock & fan & tape & shovel \\
\hline brush & flashlight & lamp & pumpkin \\
\hline pumpkin & balloon & rope & violin \\
\hline rope & teapot & scarf & flashlight \\
\hline shovel & balloon & pumpkin & lamp \\
\hline mailbox & strawberry & truck & belt \\
\hline
\end{tabular}




\begin{tabular}{|llll|} 
roller skate & flashlight & squirrel & brush \\
truck & violin & shovel & dress \\
squirrel & roller skate & belt & fan \\
\hline
\end{tabular}


Table 1. Participant Demographic and Neuropsychological Data by Group

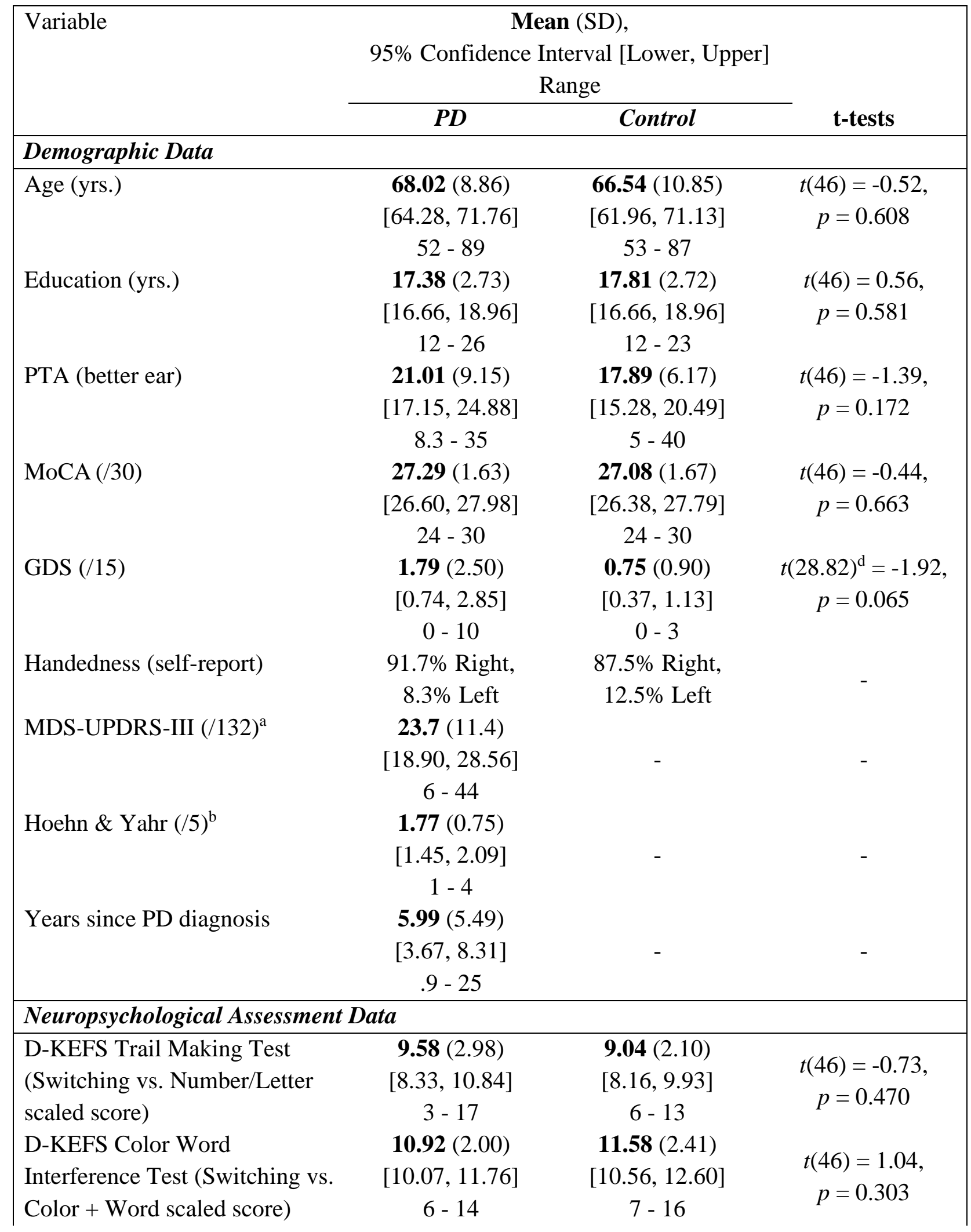




\begin{tabular}{|c|c|c|c|}
\hline $\begin{array}{l}\text { Digit Span Backwards (scaled } \\
\text { score) }\end{array}$ & $\begin{array}{c}\mathbf{8 . 7 8}(2.89) \\
{[7.56,10.00]} \\
3-16\end{array}$ & $\begin{array}{c}\mathbf{8 . 7 9}(3.37) \\
{[7.37,10.22]} \\
3-15\end{array}$ & $\begin{array}{c}t(46)=0.01 \\
p=0.992\end{array}$ \\
\hline $\begin{array}{l}\text { Semantic Fluency (Animals, } \\
\text { scaled score) }\end{array}$ & $\begin{array}{c}11.75(3.14) \\
{[10.42,13.08]} \\
6-19\end{array}$ & $\begin{array}{c}\mathbf{1 1 . 0 0}(2.27) \\
{[10.04,11.96]} \\
7-16\end{array}$ & $\begin{array}{c}t(46)=-0.95 \\
p=0.347\end{array}$ \\
\hline $\begin{array}{l}\text { CLOX I (Free-draw scaled } \\
\text { score) }\end{array}$ & $\begin{array}{c}\mathbf{1 0 . 9 6}(1.81) \\
{[10.20,11.72]} \\
6-13\end{array}$ & $\begin{array}{c}11.42(1.18) \\
{[10.92,11.91]} \\
9-13\end{array}$ & $\begin{array}{c}t(39.55)^{\mathrm{d}}=1.04 \\
p=0.304\end{array}$ \\
\hline $\begin{array}{l}\text { CLOX II (Copy trial scaled } \\
\text { score) }\end{array}$ & $\begin{array}{c}\mathbf{9 . 1 7}(2.87) \\
{[7.96,10.38]} \\
1-12\end{array}$ & $\begin{array}{c}\mathbf{9 . 3 8}(3.46) \\
{[7.91,10.84]} \\
3-12\end{array}$ & $\begin{array}{c}t(46)=0.23 \\
p=0.821\end{array}$ \\
\hline Boston Naming Test (/30) & $\begin{array}{c}27.67(2.24) \\
{[26.72,28.61]} \\
22-30\end{array}$ & $\begin{array}{c}\mathbf{2 8 . 1 3}(2.33) \\
{[27.14,29.11]} \\
22-30\end{array}$ & $\begin{array}{c}t(46)=0.70 \\
p=0.491\end{array}$ \\
\hline $\begin{array}{l}\text { Northwestern Naming Battery } \\
(/ 31)\end{array}$ & $\begin{array}{c}\mathbf{3 0 . 7 4}(0.53) \\
{[30.52,30.97]} \\
29-31\end{array}$ & $\begin{array}{c}\mathbf{3 0 . 7 5}(0.68) \\
{[30.46,31.03]} \\
28-31\end{array}$ & $\begin{array}{c}t(46)=0.02 \\
p=0.984\end{array}$ \\
\hline $\begin{array}{l}\text { NAVS sentence comprehension } \\
(/ 30)\end{array}$ & $\begin{array}{c}\mathbf{2 9 . 8 8}(0.34) \\
{[29.73,30.02]} \\
29-30\end{array}$ & $\begin{array}{c}29.75(0.53) \\
{[29.53,29.97]} \\
28-30\end{array}$ & $\begin{array}{c}t(38.97)^{\mathrm{d}}=-0.97 \\
p=0.337\end{array}$ \\
\hline Pyramids and Palm Trees (/14) & $\begin{array}{c}13.92(0.28) \\
{[13.80,14.04]} \\
13-14\end{array}$ & $\begin{array}{c}\mathbf{1 3 . 9 6}(0.20) \\
{[13.87,14.04]} \\
13-14\end{array}$ & $\begin{array}{c}t(46)=0.59 \\
\mathrm{p}=0.561\end{array}$ \\
\hline $\begin{array}{l}\text { HVLT-R total recall } \\
\text { (t-score) }\end{array}$ & $\begin{array}{c}\mathbf{4 7 . 3 8}(9.16) \\
{[43.51,51.24]} \\
30-66\end{array}$ & $\begin{array}{c}49.67(7.19) \\
{[46.63,52.70]} \\
32-64\end{array}$ & $\begin{array}{c}t(46)=0.96 \\
p=0.340\end{array}$ \\
\hline $\begin{array}{l}\text { BVMT-R total recall } \\
(\mathrm{t}-\mathrm{score})^{\mathrm{e}}\end{array}$ & $\begin{array}{c}\mathbf{5 2 . 8 3}(9.06) \\
{[49.01,56.66]} \\
34-68\end{array}$ & $\begin{array}{c}\mathbf{5 3 . 9 6}(14.85) \\
{[47.69,60.23]} \\
20-73\end{array}$ & $\begin{array}{c}t(38.1)^{\mathrm{d}}=0.32 \\
p=0.753\end{array}$ \\
\hline
\end{tabular}

Note. PTA = Pure Tone Average (of 500, 1000, and $2000 \mathrm{~Hz}$ ). MoCA = Montreal Cognitive Assessment. GDS = Geriatric Depression Scale. D-KEFS = Delis-Kaplan Executive Function System. NAVS = Northwestern Assessment of Verbs and Sentences. HVLT-R = Hopkins Verbal Learning Test- Revised. BVMT-R = Brief Visuospatial Memory Test-Revised.

aAll PD participants were assessed using the Unified Parkinson's Disease Rating Scale motor section (MDSUPDRS-III; Goetz et al., 2008) and the modified Hoehn and Yahr Scale (Goetz et al., 2004) by a certified examiner. The UPDRS-III is a standardized measure of motor impairment in PD and assesses tremor, slowness (bradykinesia), stiffness (rigidity), and balance.

${ }^{\mathrm{b}}$ The Hoehn and Yahr Scale is a standardized measure of disease severity, with scores ranging from 0 (asymptomatic) to 5 (wheelchair-bound).

${ }^{\mathrm{c}}$ Calculated by averaging participants' scaled scores from: digit span backwards, D-KEFS trail-making test switching versus composite number and letter sequencing, D-KEFS color-word inhibition test switching versus 
composite color and word reading, semantic fluency, and CLOX I (Litvan et al., 2012). Scaled scores for the semantic fluency and CLOX I tests were converted from t-scores and z-scores, respectively.

dlower d.f. due to Welch's test for unequal variances

${ }^{\text {e} B V M T-R ~ n o r m a t i v e ~ v a l u e s ~ f o r ~ p a r t i c i p a n t s ~ a g e d ~ 80-89 ~ w e r e ~ d r a w n ~ f r o m ~ G a l e, ~ B a x t e r, ~ C o n n o r, ~ H e r r i n g, ~ a n d ~}$ Comer (2007) 
Table 2. Analyses of PD versus control gaze logits to the target object during predictive sentences.

\begin{tabular}{|c|c|c|c|c|c|c|c|c|c|}
\hline \multirow{3}{*}{ Fixed Effects } & \multicolumn{9}{|c|}{ Predictive Sentences: Fixations on the Target Object } \\
\hline & \multicolumn{3}{|c|}{ Agent Time Window } & \multicolumn{3}{|c|}{ Verb Window } & \multicolumn{3}{|c|}{ Target Window } \\
\hline & Estimate & S.E. & $p$ value & Estimate & S.E. & $p$ value & Estimate & S.E. & $p$ value \\
\hline Intercept & -1.441 & 0.10 & $<.001$ & -0.353 & 0.11 & $<.01$ & 0.662 & 0.18 & $<.001$ \\
\hline Linear time & 2.342 & 0.20 & $<.001$ & 0.545 & 0.12 & $<.001$ & 0.998 & 0.24 & $<.001$ \\
\hline Quadratic time & -0.659 & 0.11 & $<.001$ & 0.061 & 0.05 & 0.270 & -0.295 & 0.08 & $<.001$ \\
\hline Group (Control/PD) & 0.086 & 0.13 & 0.505 & 0.128 & 0.15 & 0.386 & 0.263 & 0.32 & 0.409 \\
\hline Group x Linear & -0.216 & 0.28 & 0.440 & -0.061 & 0.18 & 0.730 & 0.318 & 0.35 & 0.360 \\
\hline Group x Quadratic & -0.020 & 0.17 & 0.903 & -0.112 & 0.11 & 0.305 & -0.078 & 0.13 & 0.555 \\
\hline
\end{tabular}

Note: Bolded values are significant at the $p<.05$ level

Table 3. Effect of motion content on gaze logits to the target entity during predictive sentences.

\begin{tabular}{|c|c|c|c|c|c|c|c|c|c|}
\hline \multirow{3}{*}{ Fixed Effects } & \multicolumn{9}{|c|}{ Predictive Sentences: Fixations on the Target Object } \\
\hline & \multicolumn{3}{|c|}{ Agent Time Window } & \multicolumn{3}{|c|}{ Verb Window } & \multicolumn{3}{|c|}{ Target Window } \\
\hline & Estimate & S.E. & $p$ value & Estimate & S.E. & $p$ value & Estimate & S.E. & $p$ value \\
\hline Intercept & -1.486 & 0.11 & $<.001$ & -0.351 & 0.12 & $<.01$ & 0.624 & 0.18 & $<.001$ \\
\hline Linear time & 2.356 & 0.22 & $<.001$ & 0.457 & 0.13 & $<.001$ & 0.953 & 0.26 & $<.001$ \\
\hline Quadratic time & -0.609 & 0.13 & $<.001$ & 0.011 & 0.06 & 0.865 & -0.342 & 0.09 & $<.001$ \\
\hline Group (Control/PD Intercept) & -0.003 & 0.13 & 0.981 & 0.161 & 0.15 & 0.277 & 0.277 & 0.32 & 0.388 \\
\hline Motion Content (Intercept) & -0.188 & 0.18 & 0.284 & -0.005 & 0.20 & 0.982 & -0.157 & 0.18 & 0.368 \\
\hline Group x Linear & -0.194 & 0.30 & 0.510 & 0.057 & 0.19 & 0.758 & 0.506 & 0.35 & 0.152 \\
\hline Group x Quadratic & -0.073 & 0.19 & 0.703 & -0.211 & 0.13 & 0.098 & -0.030 & 0.15 & 0.842 \\
\hline Motion x Linear & 0.042 & 0.36 & 0.908 & -0.338 & 0.22 & 0.129 & -0.199 & 0.40 & 0.615 \\
\hline Motion x Quadratic & 0.181 & 0.23 & 0.427 & -0.182 & 0.13 & 0.152 & -0.188 & 0.17 & 0.272 \\
\hline Group x Motion (Intercept) & -0.336 & 0.09 & $<.001$ & 0.091 & 0.08 & 0.261 & 0.034 & 0.07 & 0.646 \\
\hline Group x Motion x Linear & 0.038 & 0.35 & 0.913 & 0.435 & 0.26 & 0.089 & 0.736 & 0.28 & $<.01$ \\
\hline Group x Motion x Quadratic & -0.271 & 0.33 & 0.407 & -0.411 & 0.25 & 0.106 & 0.237 & 0.27 & 0.386 \\
\hline
\end{tabular}

Note: Bolded values are significant at the $p<.05$ level 
Figure 1.

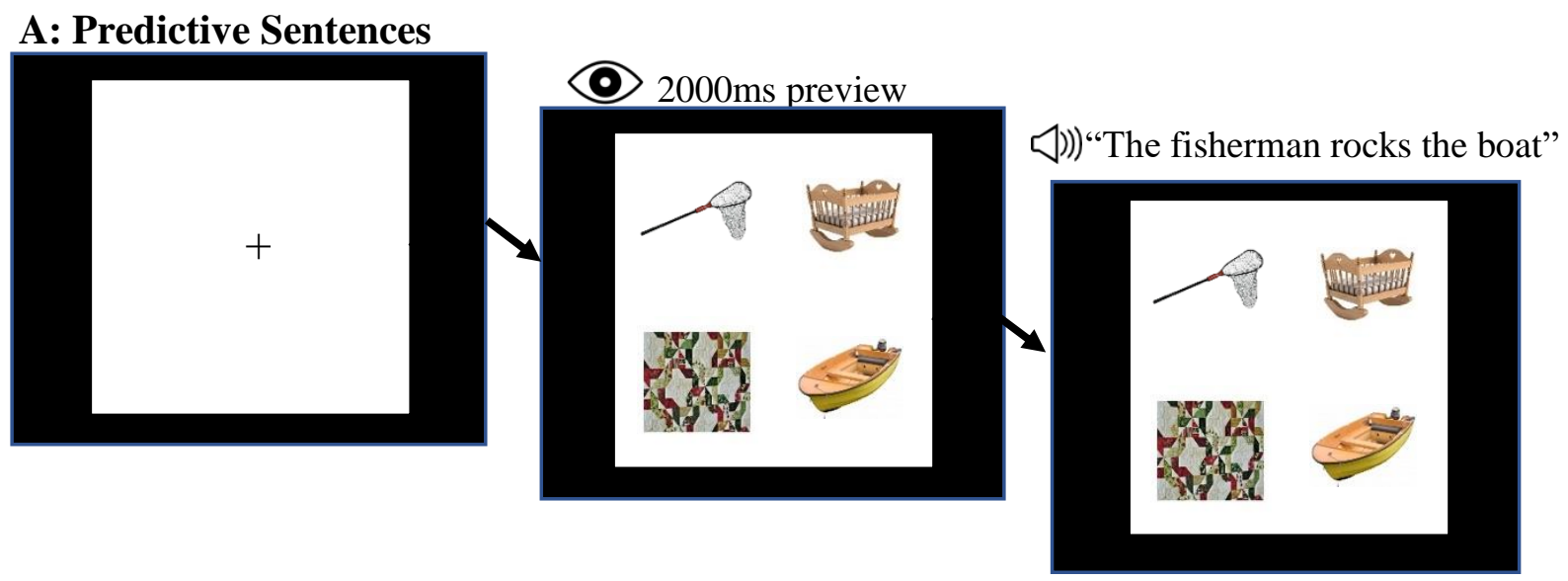

\section{B: Non-Predictive Sentences}

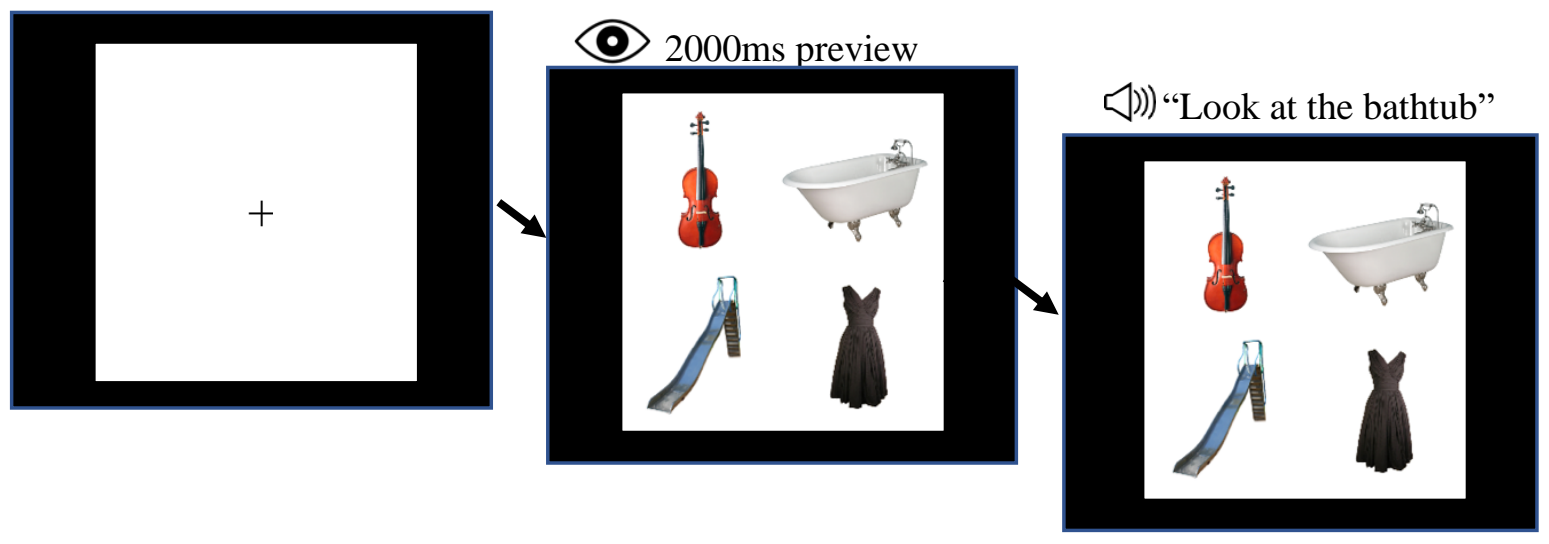


Figure 2.

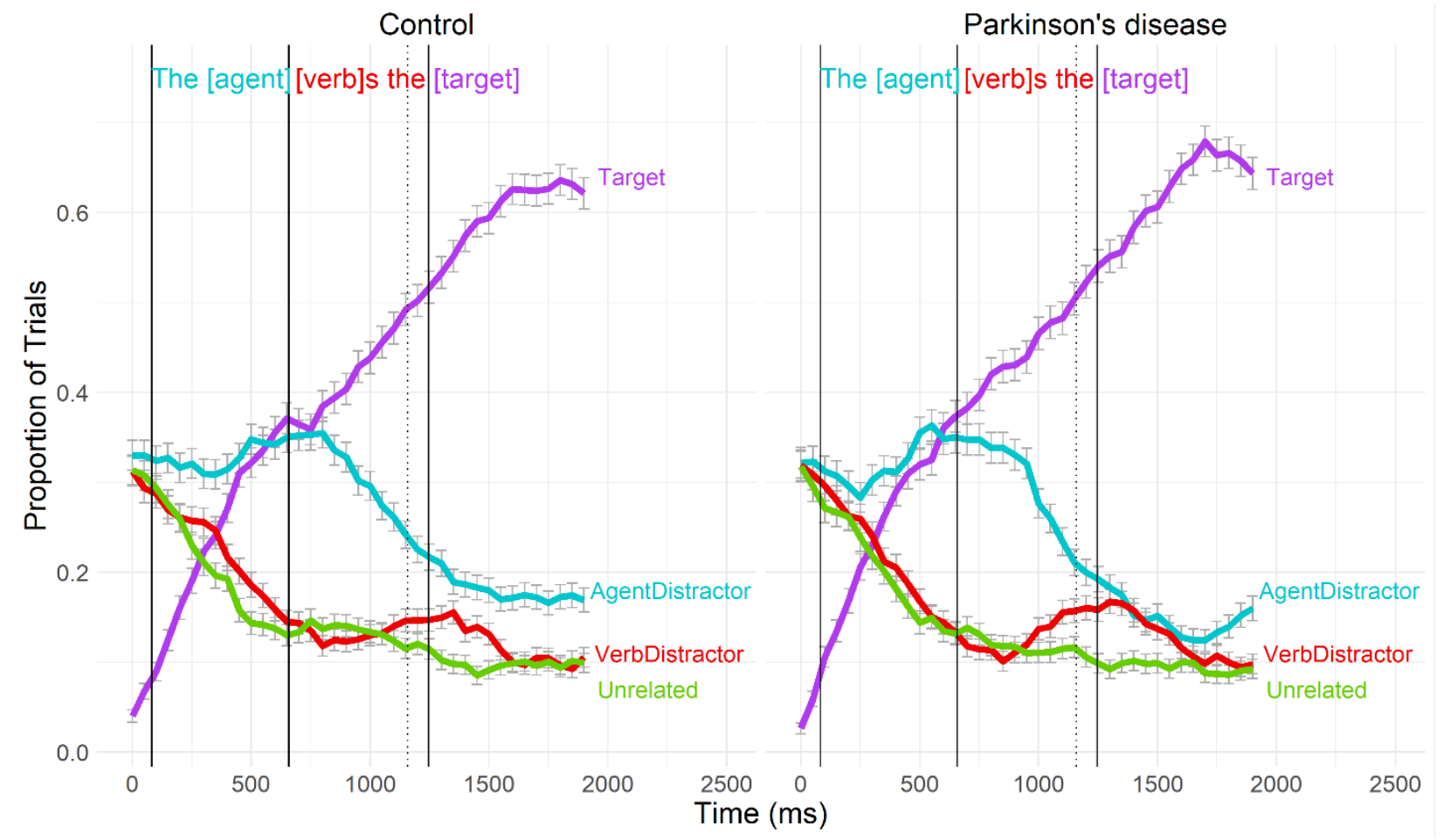


Figure 3.

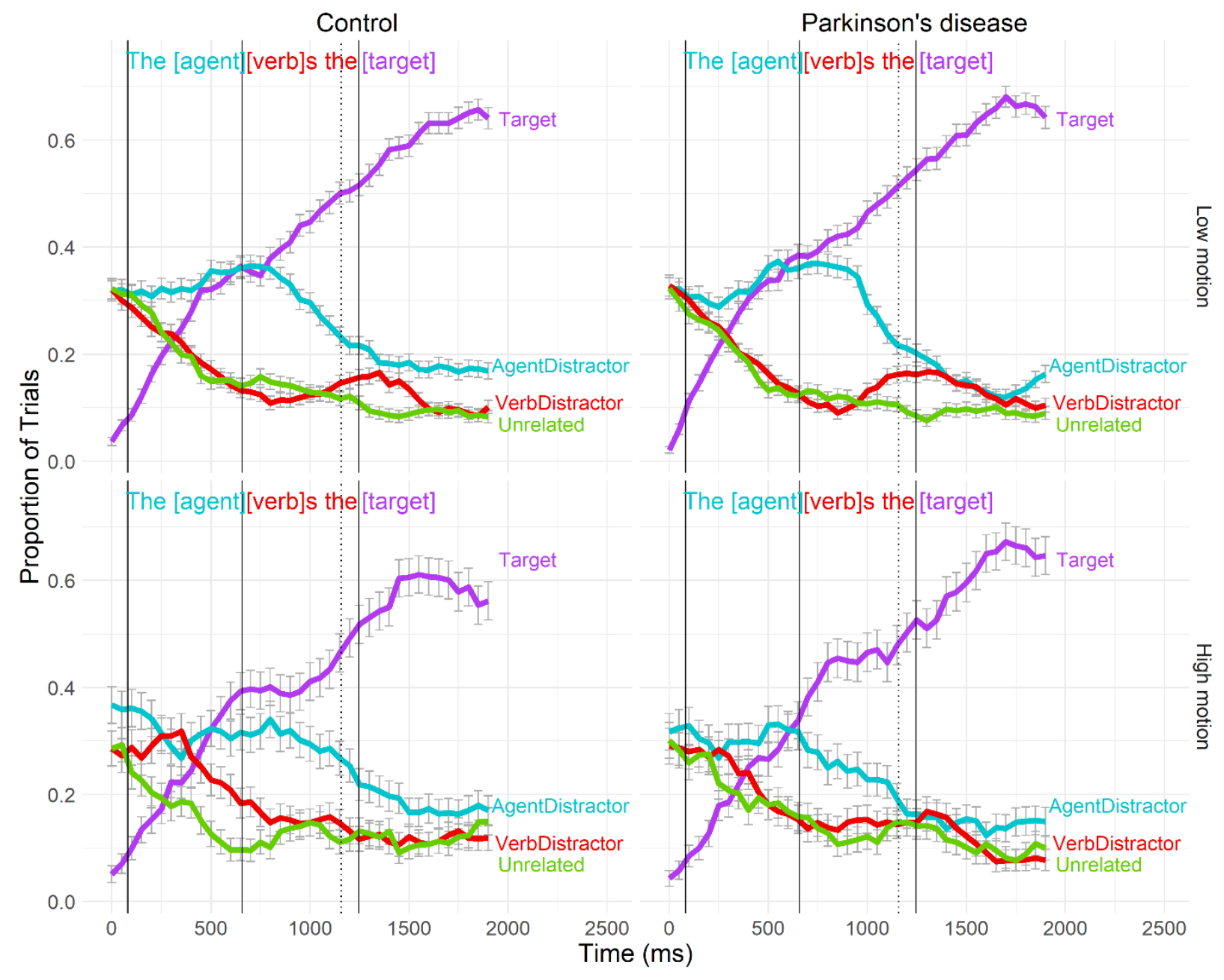


Figure 4.

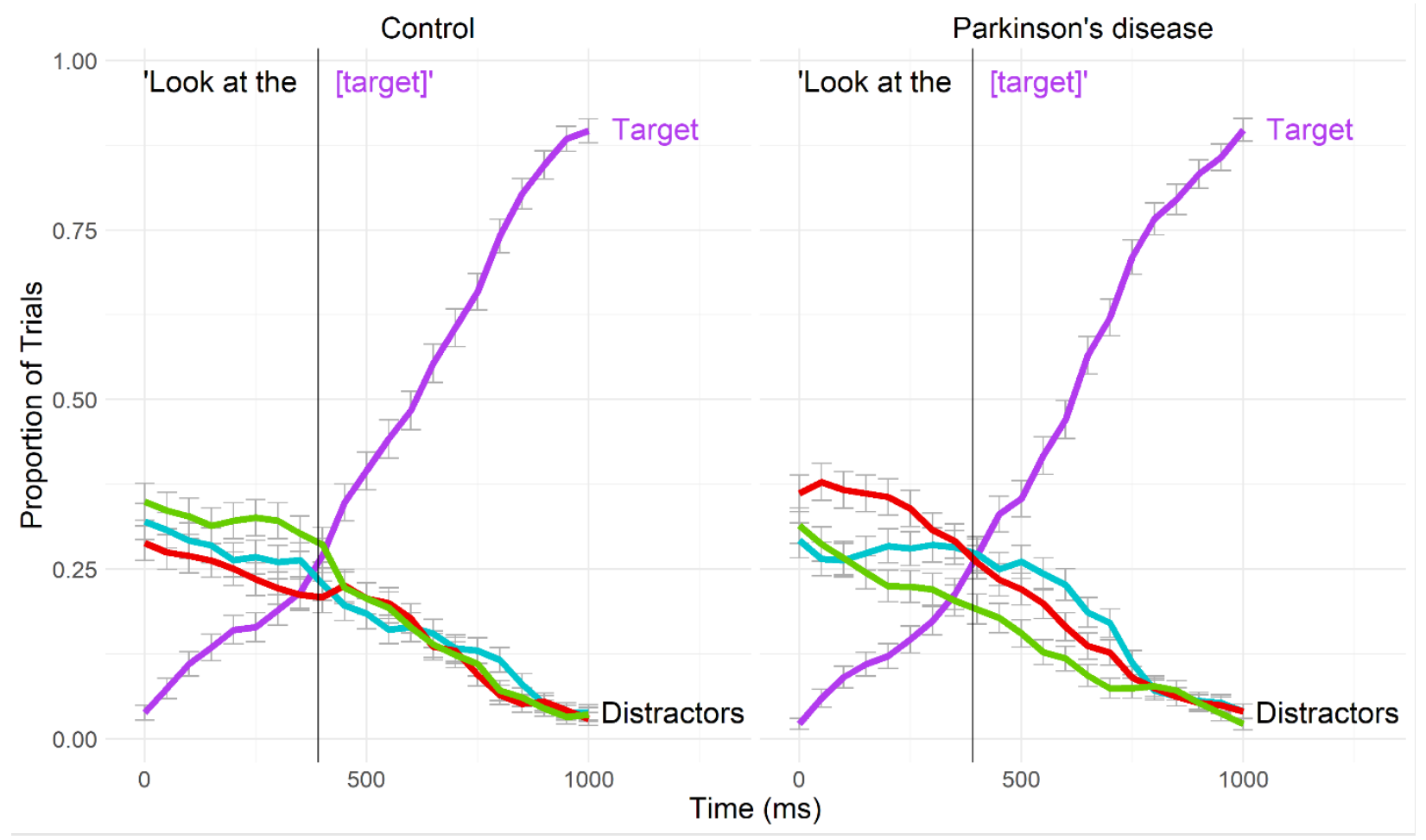


Figure 1. A schematic of the trial sequence, for predictive sentences (panel A) and non-predictive sentences (panel B). The left-most panel depicts the fixation cross, which participants had to fixate in order to launch the trial. The middle panel depicts the preview period when participants simultaneously previewed the four items. The right-most panel shows the screen layout when the sentence audio began. Images remained onscreen for the full duration of the sentence. Images were displayed in a balanced quadrant in the center of a white background, with $\sim 1.5$ inches between images horizontally, $\sim 0.5$ inches between images vertically, and $\sim 1$ inch between the edge of the image and the edge of the white portion of the screen.

Figure 2. Gaze data by group in predictive sentences. Binned binomial gaze probabilities to each area of interest, averaged across subjects and trials over the duration of the predictive sentences for controls (left) and PD participants (right). The $\mathrm{x}$-axis reflects the elapsed time in the trial in milliseconds, offset by $200 \mathrm{~ms}$ to account for saccade programming/launching time. The solid vertical lines mark the onset of the agent, verb, and target words. The dotted vertical line marks the end of the verb statistical analysis window (which extends only partially into the post-verb article). Error bars represent standard error of the mean.

Figure 3. Gaze data by group and motion content in predictive sentences. Binned binomial gaze probabilities to each area of interest, averaged across subjects and trials over the duration of the predictive sentences for: Controls $\mathrm{x}$ Low motion (upper left), Controls x High motion (lower left), PD x Low motion (upper right), PD x High motion (lower right). The $\mathrm{x}$-axis reflects the elapsed time in the trial in milliseconds, offset by $200 \mathrm{~ms}$ to account for saccade programming/launching time. The solid vertical lines mark the onset of the agent, verb, and target words. The dotted vertical line marks the end of the verb statistical analysis window (which extends only partially into the post-verb article). Error bars represent standard error of the mean.

Figure 4. Gaze data by group in baseline sentences. Binned binomial gaze probabilities to each area of interest (AOI), averaged across subjects and trials over the duration of the non-predictive sentences for control participants (left) and PD participants (right). The x-axis reflects the elapsed time in the trial in milliseconds, offset by 200ms to account for saccade programming/launching time. The vertical line marks the onset of the target word. Error bars represent standard error of the mean. 